\title{
Managing customer satisfaction: digital applications for insurance companies
}

\author{
Christian Eckert $^{1,2} \cdot$ Christof Neunsinger $^{2} \cdot$ Katrin Osterrieder $^{2} \mathbb{D}$
}

Received: 14 June 2021 / Accepted: 1 November 2021 / Published online: 7 February 2022

(c) The Author(s) 2022

\begin{abstract}
Customer satisfaction management is increasing in importance within the insurance industry. In particular, to define a customer-oriented strategy, installing digital applications based on technologies, e.g. including artificial intelligence or cloud computing, ranks among the major strategic challenges. Against this background, the aim of this paper is to take an integrated perspective on managing customer satisfaction and the digital transformation. Towards this end, we identify and assess a set of digital applications, as a result of a comprehensive review of 106 academic papers and publications of the industry and supervisory authorities. We illustrate the opportunities to increase customer satisfaction and emphasise their impact on insurers at four major customer touch points: contract conclusion, contract modifications, the event of damage and further contacts. Our results are strategic measures to strengthen the position for sales and marketing, to simplify standard processes and to increase efficiency and interaction with the customer.
\end{abstract}

Keywords Digital applications · Customer satisfaction · Insurance innovation

An earlier version of the paper is included in the doctoral thesis K. Osterrieder, "Current Issues in the Strategic Management of Insurance Companies: Essays on the Future of Mobility, Digital Applications, Customer Satisfaction and Collaborations with MGA-InsurTechs", FriedrichAlexander-University Erlangen-Nürnberg, 2021.

Katrin Osterrieder

katrin.osterrieder@fau.de

Christian Eckert

christian.eckert@hs-coburg.de

Christof Neunsinger

christof.neunsinger@fau.de

1 Department of Business and Economics, Coburg University of Applied Sciences and Arts, Friedrich-Streib-Straße 2, 96450 Coburg, Germany

2 School of Business, Economics and Society, Friedrich-Alexander University Erlangen-Nürnberg (FAU), Lange Gasse 20, 90403 Nürnberg, Germany 


\section{Introduction}

In the past, customer satisfaction in insurance has not been widely discussed as a key steering figure for insurance management, and academic research on customer satisfaction in the insurance industry is notably low compared with other sectors (e.g. Brutyan et al. 2019; Jahnert and Schmeiser 2021; Pooser and Browne 2018). Today, digitalization affects and transforms customer behaviour, customer expectations and customer requirements (Catlin et al. 2015; Cebulsky et al. 2018; Lyskawa et al. 2019). Private insurance customers experience highly transparent, fast service processes in other industries (e.g. firms such as Amazon setting the benchmark for best practices) and transfer their requirements to the quality of the insurance customer experience (e.g. Catlin et al. 2015; Hall 2017; Müller et al. 2015). Moreover, the insurance market observes the phenomenon of InsurTechs, which is beneficial for customers, as they operate flexibly and simplify innovation processes (e.g. Eling and Lehmann 2018; Grima et al. 2020). Hence, managing customer satisfaction has become more important and more challenging for incumbent insurance companies.

At the same time, digitalization also provides considerable benefits for insurance companies in this regard. By enhancing the customer experience (Eling and Lehmann 2018), bringing policyholders and insurance companies closer together (Kotalakidis et al. 2016) and widening the role of insurance companies to become the insured's risk manager, digitalization might help improve customer satisfaction (e.g. IAIS 2018), as insurance companies evolve from pure risk protectors to risk predictors and preventers (Kelley et al. 2018; Schmidt 2018).

Previous literature reveals that customer satisfaction drives customer loyalty and leads to fewer customer complaints (Fornell et al. 1996; Helgesen 2006; Heskett et al. 1994). Moreover, there is an abundance of literature investigating customer satisfaction in general (for an overview, see, e.g. Arora and Narula 2018). In particular, Oliver $(1977,1980)$ developed the expectation confirmation theory, which argues that customer satisfaction is mainly driven by customer expectations and perceived performance. Outperforming customer expectations with the product or service leads to higher customer satisfaction, while underperforming decreases customer satisfaction (Oliver 1977, 1980). In the context of insurance customer satisfaction, existing empirical evidence indicates that lower expenses and combined ratios in the presence of satisfied customers are due to an increasing number of renewed contracts (instead of new policies), with reduced costs for customer acquisition. Therefore, increasing customer satisfaction is discussed to enhance the profitability of insurance operations (Pooser and Browne 2018). ${ }^{1}$ Jahnert and Schmeiser (2021) extend the investigations on the relation between customer satisfaction and profitability in the insurance industry by analysing data at the level of individual customers stemming from a Swiss non-life insurance

\footnotetext{
1 The related dataset of Pooser and Browne (2018) refers to automobile insurers in the US. The authors state the positive impact of customer satisfaction on the overall profitability of automobile insurers. The investigations specifically refer to revenue, profitability and prices in terms of the financials of insurance companies. Due to better retention and recommendation rates of satisfied customers to friends and family, the authors identify the potential to lower customer acquisition costs (Pooser and Browne 2018).
} 
company. Moreover, due to the widespread utilisation of information technology, the option to conduct comprehensive research from the perspective of customers in relation to the characteristics of insurance products, prior to purchasing them, becomes increasingly relevant (e.g. Mau et al. 2015): customers can easily compare products using comparison portals or conveniently buy products online, which is especially important for property and casualty insurance (e.g. Woo-Yeon et al. 2021). To further underpin the relevance of digitalization, recent empirical works discuss process improvements toward customer centricity (e.g. Kreuzer et al. 2020), customer engagement through value co-creation (e.g. Chen and Chen 2017), the trade-off between customisation and complexity (e.g. Grösch and Steul-Fischer 2017; Leischnig et al. 2018), the decisive function of intermediaries (e.g. Dominique Ferreira 2018) and the reliability and responsiveness of customer support (e.g. Ramamoorthy et al. 2018) as prerequisites for customer satisfaction in the insurance industry. As customer satisfaction builds trustful relationships, it thereby increases policyholders' willingness to disclose personal data, which in turn unlocks various benefits for insurers using digital technologies (Steiner and Maas 2018).

However, to the best of our knowledge, there is a lack of academic and practitioneroriented research focusing on the benefits and opportunities of digital applications when managing customer satisfaction from the perspective of insurers, with a focus on the major customer touch points. By including them, we extend the investigations of Eckert and Osterrieder (2020), who take a more technical perspective on implementing digital technologies (e.g. big data, artificial intelligence, cloud computing, the Internet of Things and distributed ledger technology) and discuss the interdependencies between them. In particular, we contribute to previous work by identifying and analysing a set of digital applications. We distinguish between front-end and back-end functionalities and assess the opportunities of these applications at the major customer touch points of insurers, including contract conclusion, contract modifications, the event of damage and further contacts. Hence, our results provide insights and guidance for managing customer satisfaction in a targeted manner on the corresponding customer touch points (e.g. allow a focus on customer touch points, where customer satisfaction is currently low). For each incorporated digital application, we additionally provide a set of necessary requirements, so as to install these and comprehensively discuss their limitations due to concerns, e.g. related to data utilisation and customer attitudes regarding new technologies or regulatory hurdles.

The paper is structured as follows. The next section describes the theoretical background and addresses the terminology. We present the set of digital applications and focus on their benefits and opportunities at the four major customer touch points in the subsequent two sections. Then, we discuss the limitations and derive the related requirements for insurers. The final section summarises the results.

\section{Theoretical background: methodology and analysis}

The paper focuses on a comprehensive assessment of digital applications for insurers when managing customer satisfaction. To this end, we create, review and assess a comprehensive literature data sample, which consists of 106 articles in total and 
incorporates academic research and the publications of industry experts and supervisory authorities. ${ }^{2}$ The sample is based on the review approach of Eckert and Osterrieder (2020) and is a result of key word searches including 'insurance' AND 'artificial intelligence', 'insurance' AND 'big data', 'insurance' AND 'blockchain', insurance' AND 'cloud computing', 'insurance' AND 'digitalization', 'insurance' AND 'digital transformation', 'insurance' AND 'distributed ledger technology' as well as 'insurance' AND 'internet of things'. We thereby implement the searches in the selected journal databases (ABI/INFORM Collection, Business Source Complete, EconLit Full Text), and amend the focus of screening and selecting the resulting articles in relation to the effects on customer satisfaction. Besides, to get a reasonable understanding of the current state of research on customer satisfaction in the insurance industry, we search the Scopus database for scientific journals using the queries 'customer' AND 'satisfaction' in the field of business, management and accounting. Finally, to reduce the risk of omitting literature important to this work, we extend our scope to Google Scholar and Google, to incorporate recent discussions in the industry and additionally review and assess the cited references (see also Eckert and Osterrieder 2020; Gatzert and Osterrieder 2020).

Based on this, we have created a set of digital applications for insurers and explain why and how these applications support managing customer satisfaction, which "evaluates whether the customer was satisfied with the insurance services, insurance transaction, and their relationship with the insurance company" (Nguyen et al. 2018 , p. 4). ${ }^{3}$ To comprehensively assess the aforementioned set of digital applications for insurers, we consider versatile internal options of utilisation that affect different strategic levels within an insurance company. For this reason, we cluster the set of digital applications as a first step based on a categorisation of their main focus on automating or digitally enhancing back-office functionalities, front-office functionalities, or a combination of both (e.g. Günzel and Holm 2013; Marquez 2010; Osterwalder and Pigneur 2010):

- Back-office functionalities are related to enhancing the efficiency of insurers by affecting key resources, key activities, key partners or the cost structure.

- Front-office functionalities comprise the value-driven parts of insurers' business models by affecting the value proposition, channels, customer relationships or revenue streams.

\footnotetext{
2 The literature data sample consists of 83 academic articles that are relevant to the subject of the research questions. These 83 articles (mainly peer-reviewed, as, for instance, relevant working papers are included) represent the foundation from which we draw conclusions for the paper. However, we consider 23 web-references as a supplement to capture recent discussions of the topical strategic issue of managing customer satisfaction in insurance companies. Even if the content of the web-references incorporates non-peer-reviewed documents, such as reports or studies of industry representatives (e.g. consultancy companies), that are not representative of scientific knowledge, considering the articles allows us to draw further implications from current developments in practice.

${ }^{3}$ See Giese and Cote (2000) for a detailed literature review and discussion concerning the definition of customer satisfaction.
} 
Figure 1 illustrates the integrated perspective on the digital transformation and customer satisfaction in the insurance industry. Moreover, it provides an overview of the analysis along with definitions of the relevant terminology and substantiates the derivation of the relevant research questions. In general, the relevance of the illustrated research questions is underpinned by the importance of managing customer satisfaction in the insurance industry: academic work connects customer satisfaction in the insurance industry to customer loyalty (e.g. Abu-Salim et al. 2017; Lee 2019; Nguyen et al. 2018; Ruefenacht 2018), which is important due to its potential impact on the (current and future) economic results of insurance companies (e.g. Eskildsen and Kristensen 2008; Trautinger 2015). In addition to that, Jahnert and Schmeiser (2021), for instance, emphasise the vast amount of non-insurance literature that highlights customer satisfaction as an important factor for a firm's profitability, and state the necessity of differentiated considerations of the effects for the insurance industry. Extending the focus to academic work from outside the insurance industry, empirical findings state the positive impact of customer satisfaction on organisational performance (Ittner and Larcker 1998), such as stock prices (e.g. Aksoy et al. 2008; Fornell et al. 2006, 2016), cash flows (e.g. Gruca and Rego 2005), or Tobin's Q (e.g. Anderson et al. 2004). Moreover, customer satisfaction increases the market share of firms and creates barriers to customer defection (e.g. Fornell 1992; Matzler and Hinterhuber 1998). Thus, firms benefit from cost savings as retaining already existing customers is typically less expensive than acquiring and nurturing relationships of new customers (e.g. Mittal and Kamakura, 2001; Reichheld and Sasser 1990).

Regarding the drivers of customer satisfaction, previous research additionally points to the customers' perceived value of a product or service (e.g. Dodds et al. 1991; Parasuraman 1997). According to existing research (e.g. Anjum et al. 2016; Dodds et al. 1991; Fornell et al. 1996; Johnston 1995; Parasuraman et al. 1988; Zeithaml et al. 1990), the perceived value itself is driven by corporate image, service quality and price (see, e.g. Nguyen et al. 2018 for an overview in the context of the insurance industry).

When managing customer satisfaction, it is of great relevance to focus on the customer touch points during the customer journey, as these generate customer perceptions. These customer touch points are commonly used when measuring customer satisfaction (e.g. AssCompact 2020). For this reason, we cluster the illustrated digital applications in terms of applicability for each of those touch points: contract conclusion, policy modifications, event of damage and further contacts. The latter includes points of contact, which are related to providing additional services, offering information on general features or placing general advertisements (e.g. provided by insurance brokers or agents). By integrating the categorisation into our analysis, we are able to derive a set of strategic measures for insurers, aimed at specific areas of the customer journey (e.g. by focusing customer satisfaction management on the touch points, which are characterised by a low customer satisfaction level). 


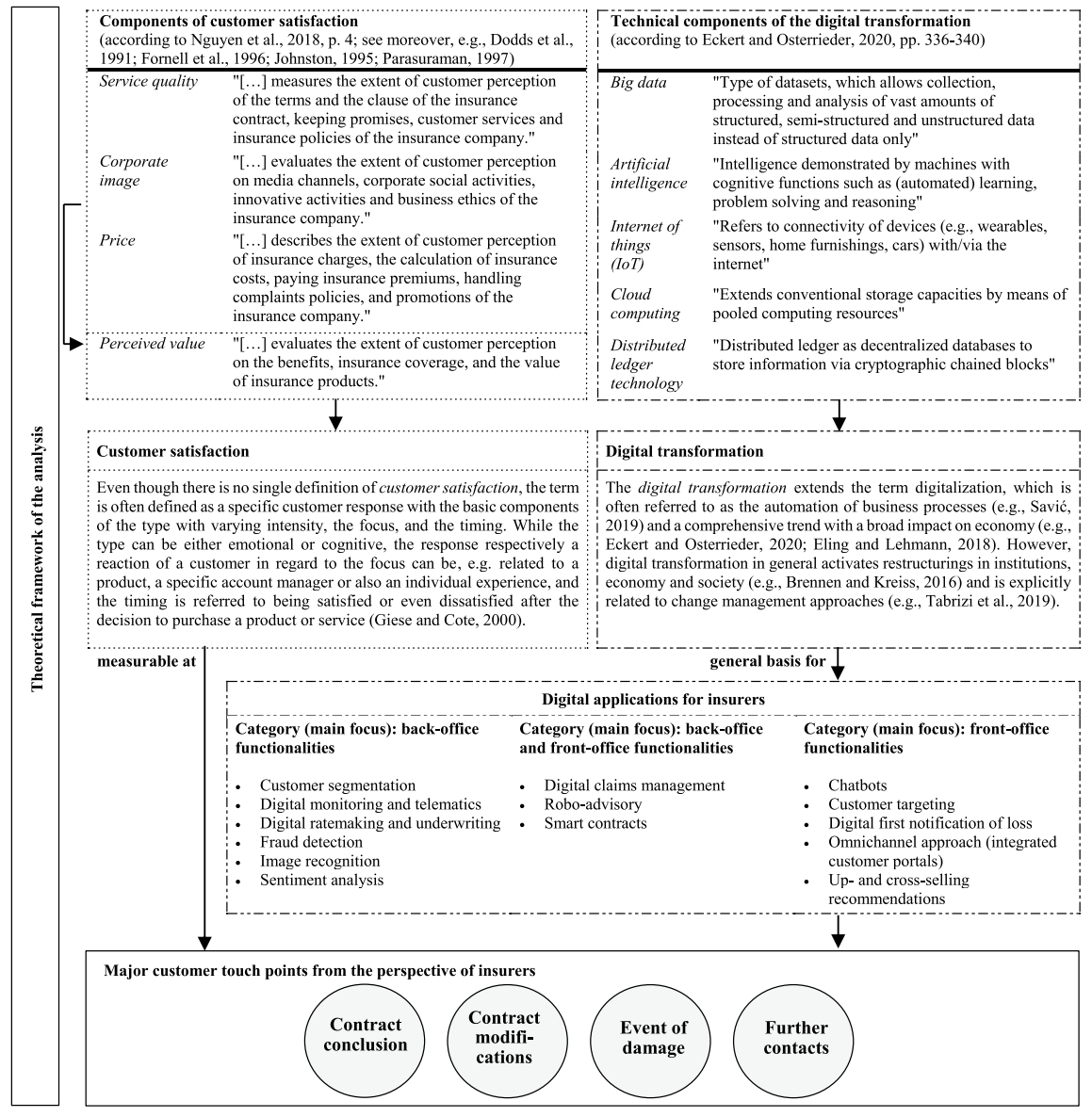

Which digital applications support managing customer satisfaction at the customer touch points? Derivation of subquestions with related research objectives:

What are the functionalities and main characteristics of the digital applications?

What are the resulting benefits and the opportunities at each major customer touch point?

What are the requirements and limitations for the implementation?

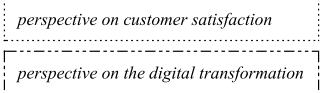

Fig. 1 Derivation of the research questions based on the theoretical background of customer satisfaction and digital transformation

\section{The set of digital insurance applications: overview and characteristics}

As previously explained, the set of digital applications for insurers was created based on the literature data sample. By reviewing and analysing the incorporated articles, we further develop the investigation of Eckert and Osterrieder (2020) and consider 
the following fields of applications: customer segmentation (e.g. Heo and Grable 2017; Owadally et al. 2019), customer targeting (e.g. Venkatesh 2019), up- and cross-selling opportunities (e.g. Owadally et al. 2019), the omnichannel approach with integrated customer portals (e.g. Cebulsky et al. 2018; Matouschek and von Hülsen 2015), digital monitoring and telematics (e.g. EIOPA 2019; Hall 2017; Lehrer et al. 2018; Spender et al. 2019), and enhanced fraud detection in respect of efficiency, speed advantages and the potential to lower claims costs (e.g. Deloitte 2017; EIOPA 2019; Garde, 2017). We moreover focus on sentiment analysis along with image recognition (e.g. Deloitte 2017; EIOPA 2019; Eling and Lehmann 2018), digital claims management (e.g. EIOPA 2019; Hall 2017; Lehrer et al. 2018) and the digital first notification of loss (e.g. EIOPA 2019), digital and automated underwriting and ratemaking (e.g. EIOPA 2019; Helfand 2017; Xu and Hoesch 2018; Venkatesh 2019), smart contracts (e.g. Baron and Chaudey 2019; Gatteschi et al. 2018), robo-advisory (e.g. OECD 2017) and chatbots (e.g. Gruhn, 2018; Riikkinen et al. 2018). Table 1 provides a comprehensive overview of the incorporated set of digital applications categorised by their main focus on back-office functionalities, frontoffice functionalities, or both, including a description and the major characteristics.

Note that some of the digital applications can be seen on different hierarchical levels. For instance, image recognition can be also used to improve fraud detection. Practical literature (e.g. Bitkom 2018) often refers to a 'periodic table of AI' that consists of elementary applications of artificial intelligence such as image recognition or predictive inference, while applications in practice, e.g. fraud detection, are frequently a combination of these elementary applications of artificial intelligence. In this paper, we focus on the most important digital applications for insurance companies, which often consist of more than one elementary artificial intelligence/digital application and do not aim to go to the level of the elementary applications. However, the areas of applying image recognition in insurance companies go way beyond fraud detection, as explained in Table 1. For this reason, in this case the elementary application itself is important enough to be considered as a separate digital application. Moreover, fraud detection is not only improved by means of image recognition, which is why we investigate fraud detection also as a separate digital application, leading to dependencies between some digital applications in Table 1.

\section{Four major customer touch points: benefits and opportunities of digital applications}

In what follows, we discuss and assess the benefits as well as the opportunities of the presented set of digital applications, in terms of managing customer satisfaction from the perspective of insurers. Table 2 states the relevance of the applications within the displayed 'opportunity landscape' and emphasises the potential to enhance, e.g. the customer experience, but also the customer journey, based on the literature. Moreover, the specific benefits and opportunities are clustered for each of the four customer touch points (contract conclusion, contract modifications, the event of damage, further contacts). These provide the basis for the strategic decisions of insurers when evaluating applications in regard to deriving measures to 


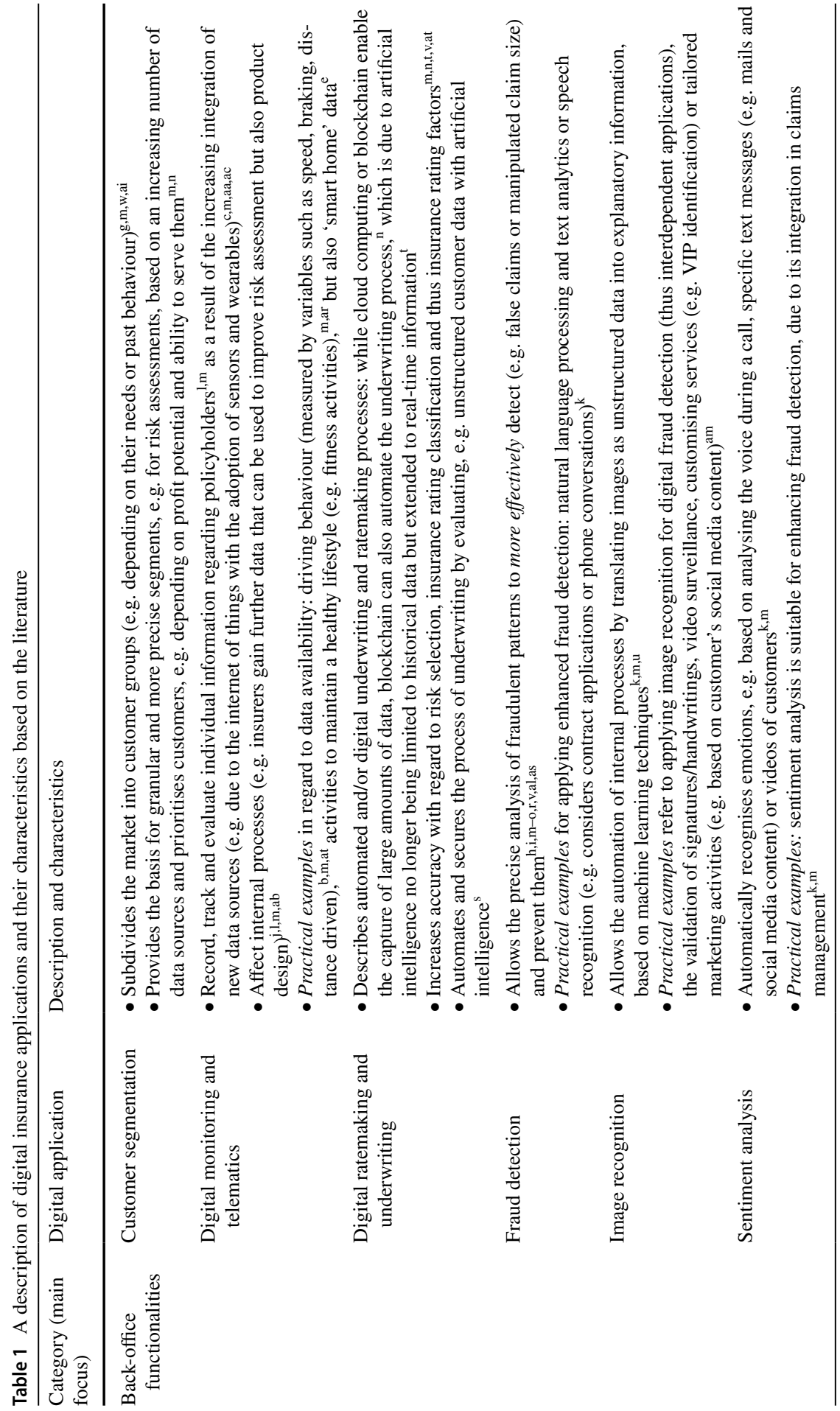

站。 


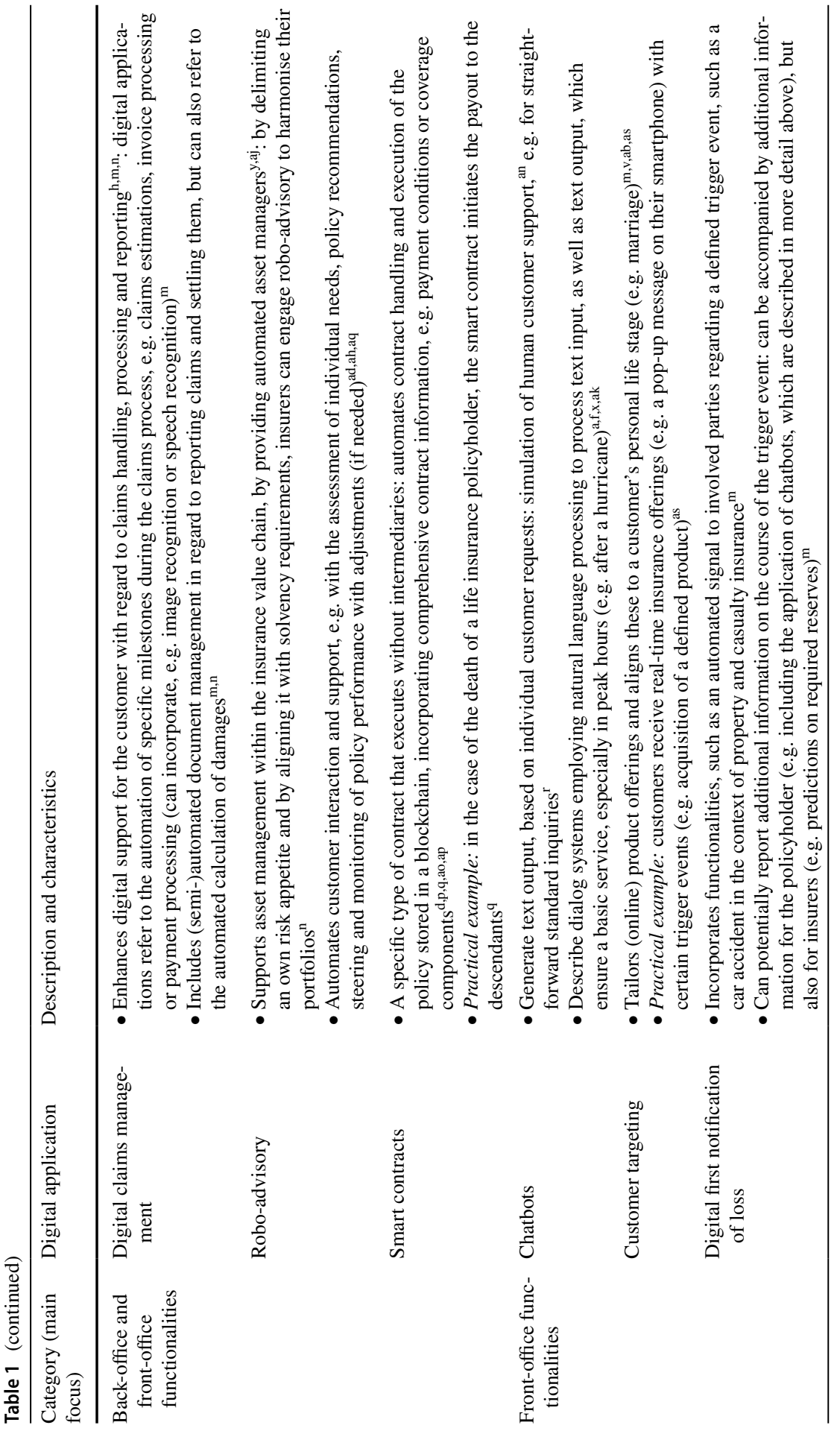




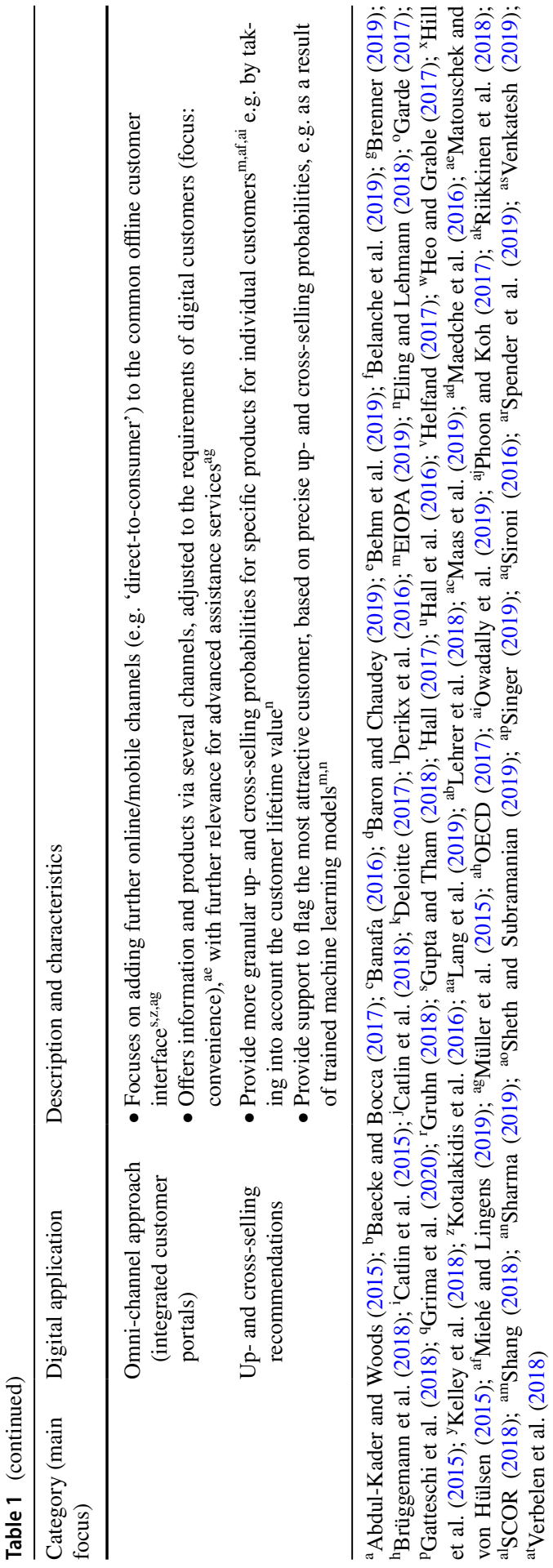

我造 


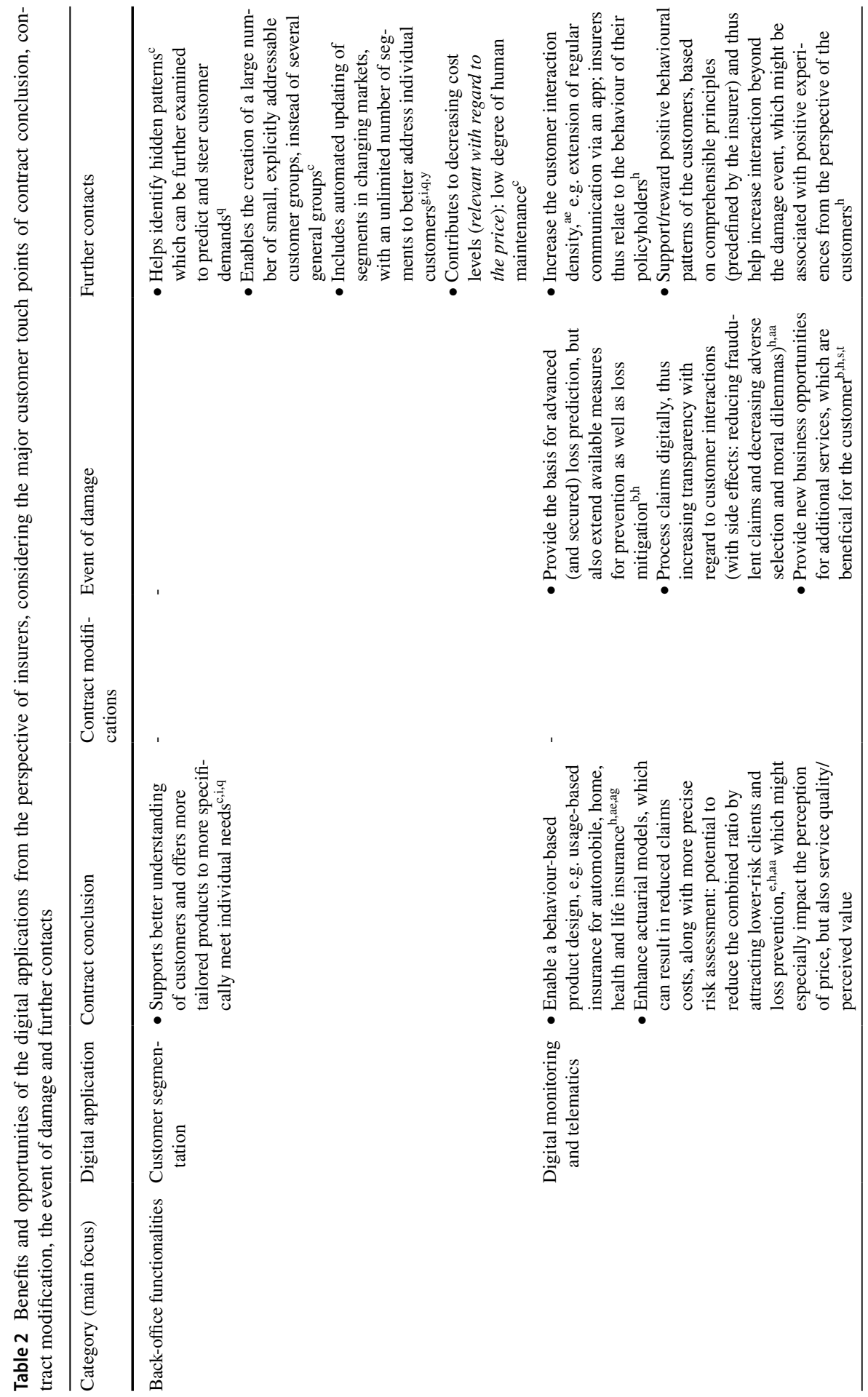




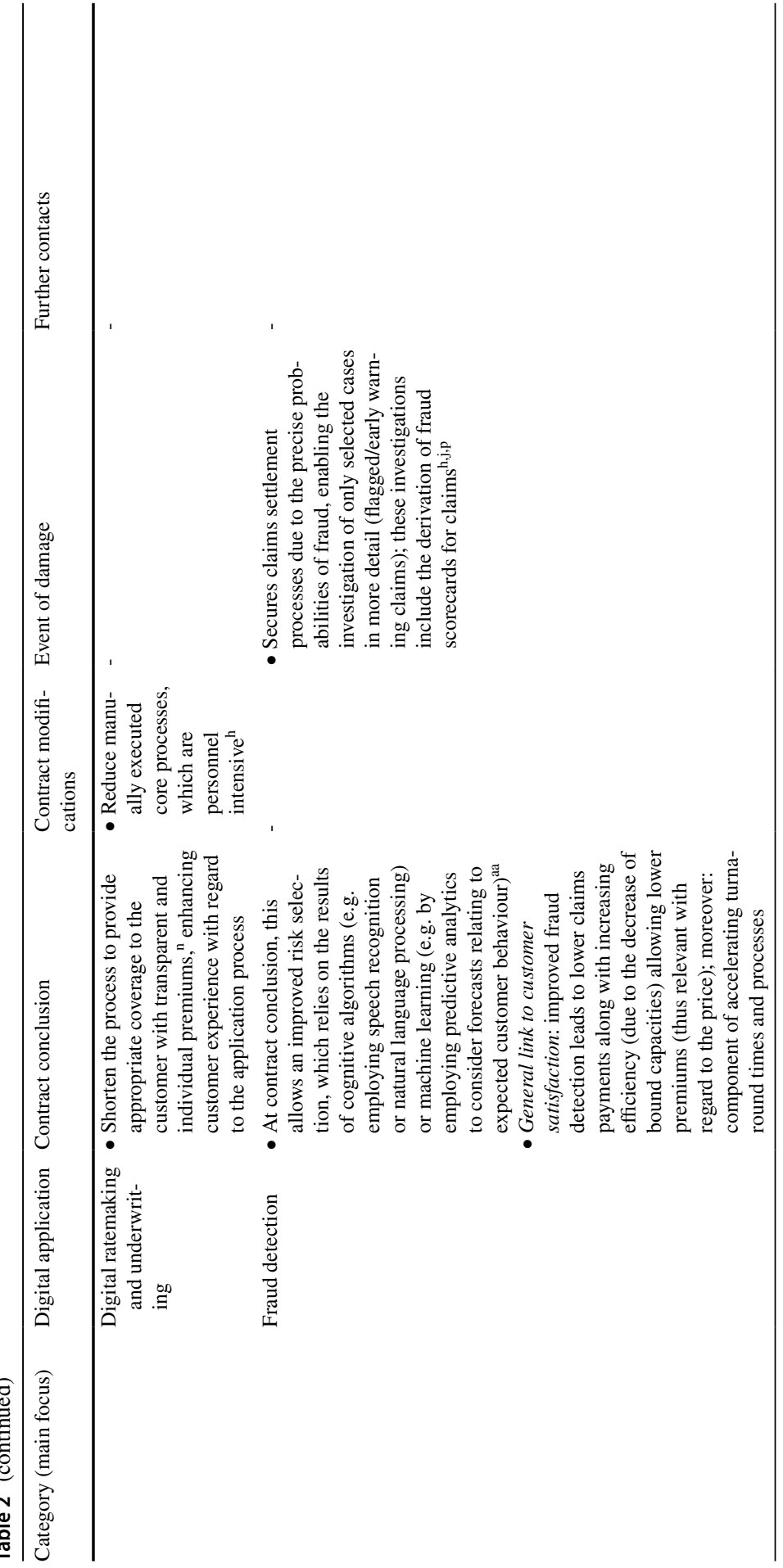

站。 


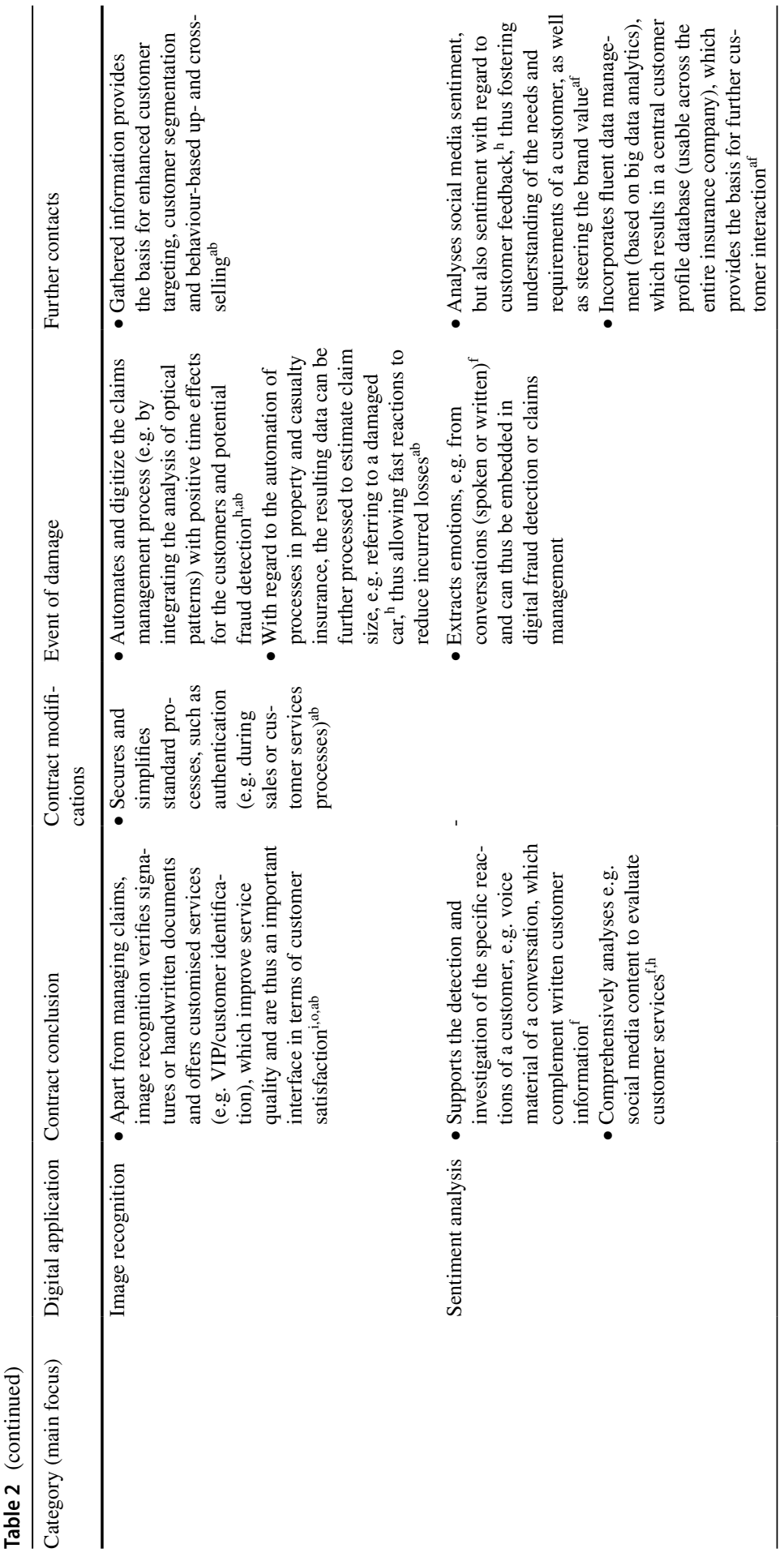




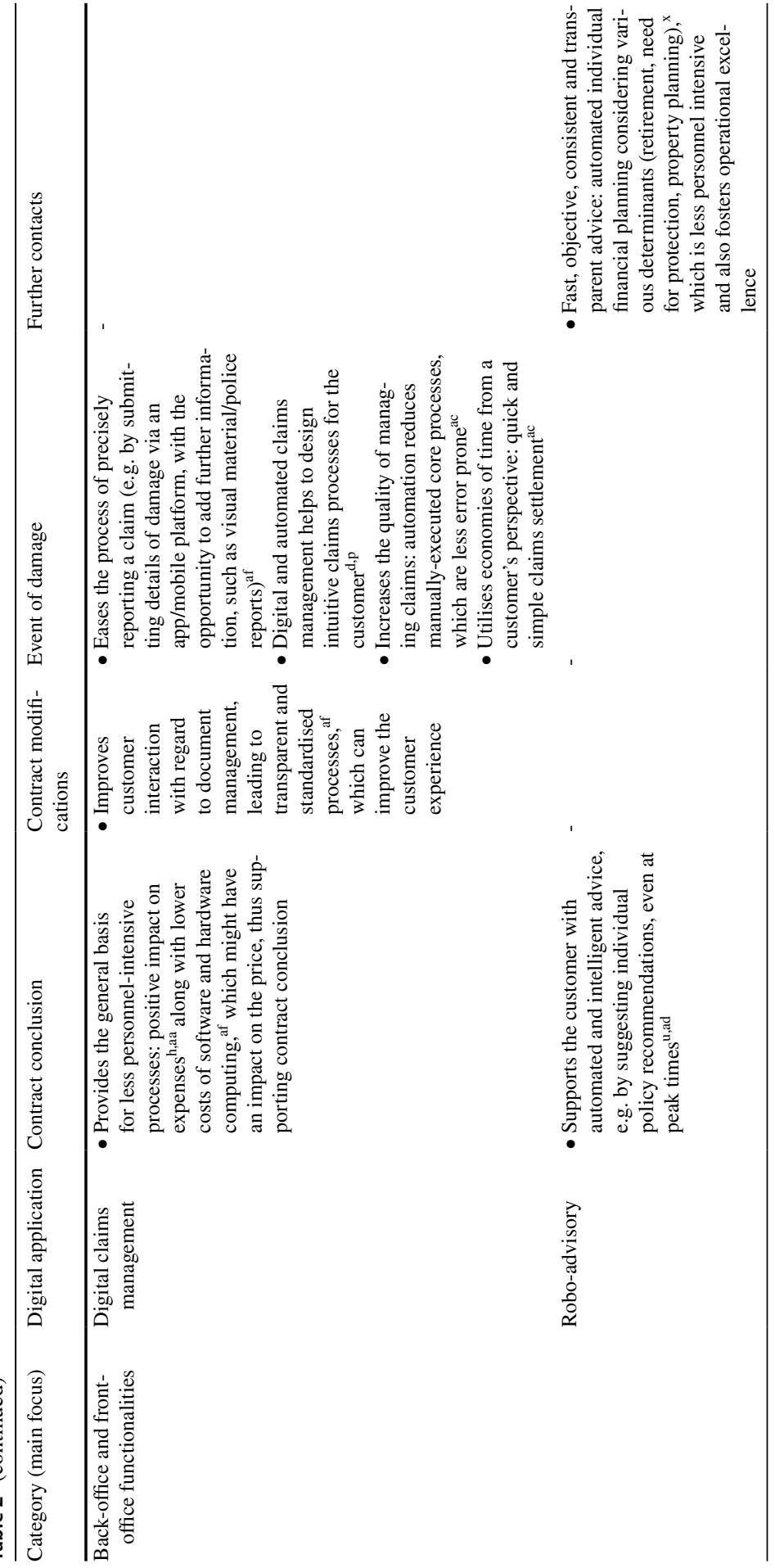

站。 


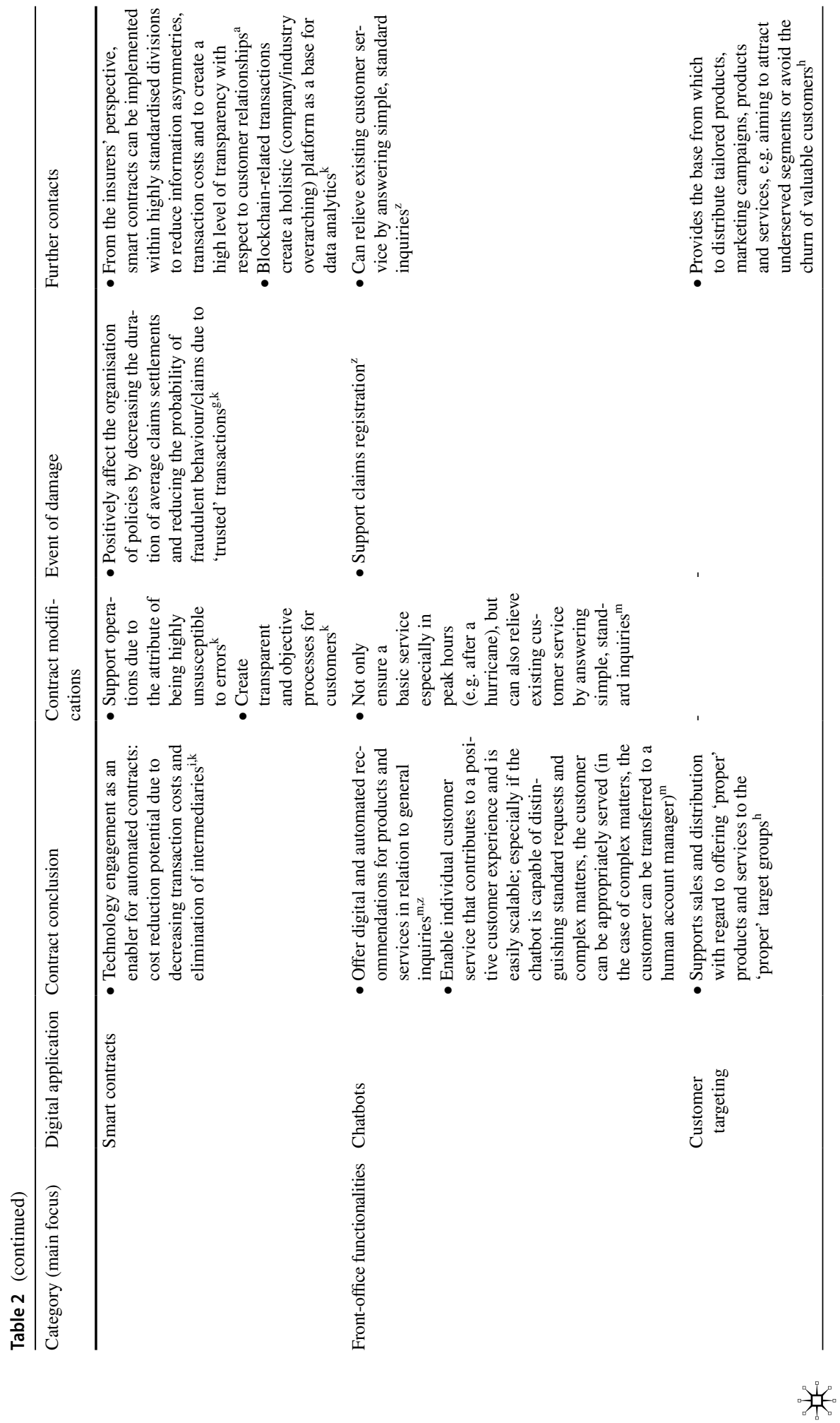




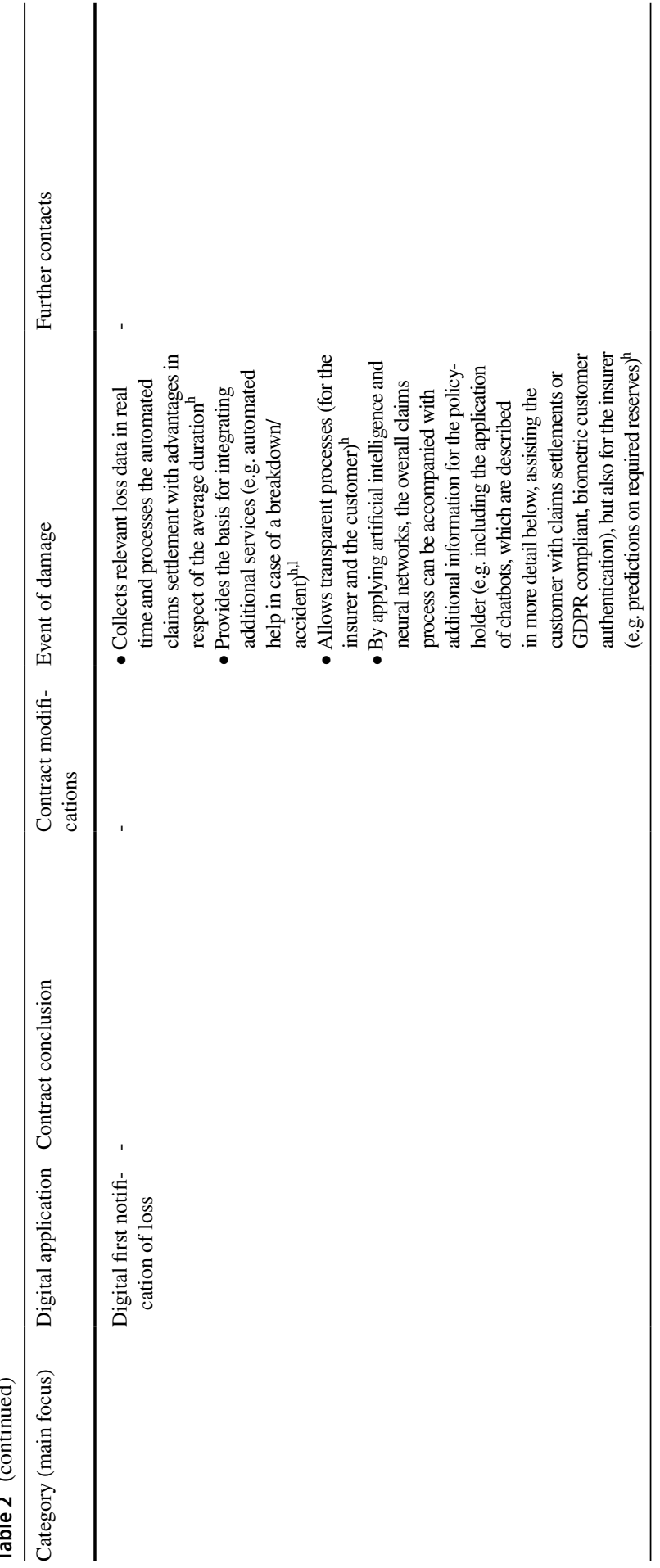

站 


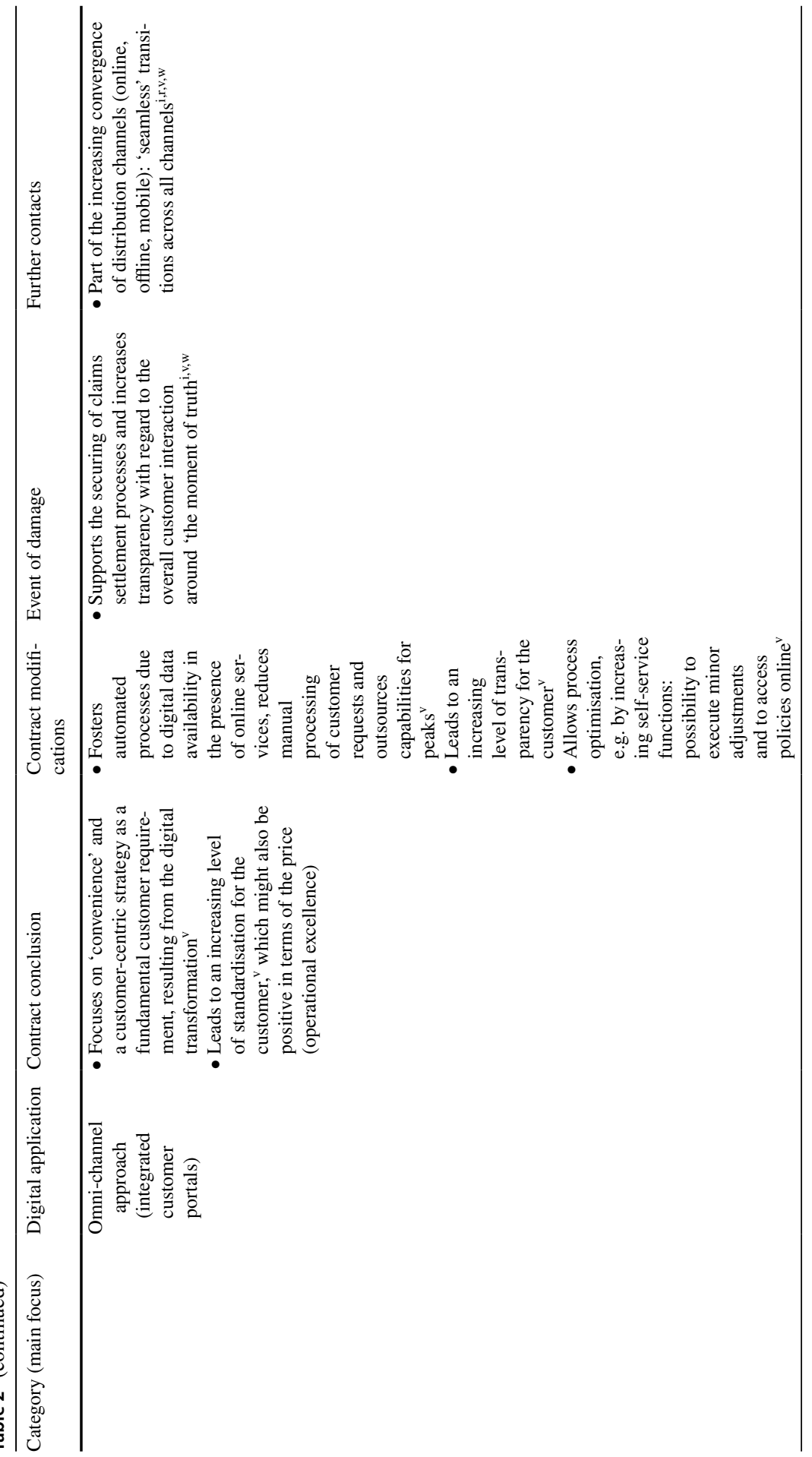




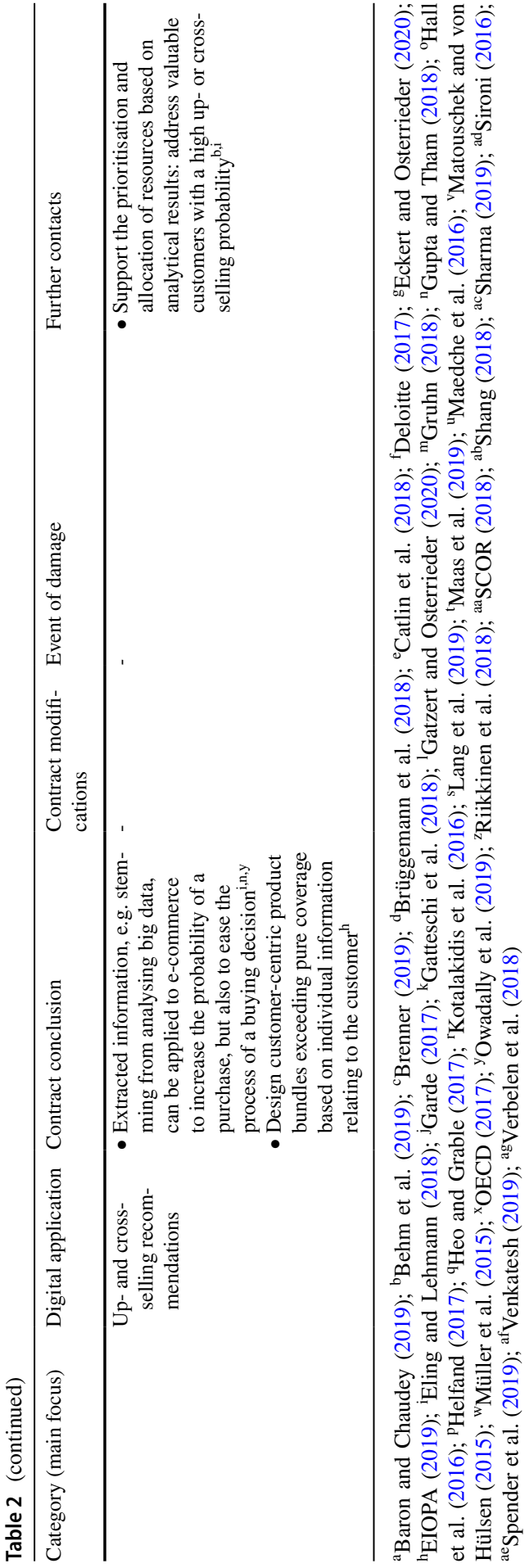

称。 
enhance customer satisfaction. While Table 2 shows the benefits and opportunities for customer satisfaction in terms of each digital application at each customer touch point in detail, the presented digital applications address all of the three components of customer satisfaction, namely service quality, corporate image and price, and therefore the perceived value (see Fig. 1). We subsequently provide a summary of the major findings aggregated for each touch point and highlight the main effects of utilising the applications as strategic measures for insurers.

\section{Contract conclusion as a customer touch point: strengthening the position for sales and marketing}

The digital applications with potential opportunities at contract conclusion are characterised by increasing customer-centricity (e.g. Matouschek and von Hülsen 2015; EIOPA 2019). In general, they aim to better understand the customers and to offer more tailored products to suit the individual needs of a customer perfectly (e.g. Brenner 2019; Eling and Lehmann 2018; Heo and Grable 2017). By building on refined customer segments of precise segmentation, for instance, customer targeting allows enhanced advertising and tailored product offers, based on comprehensive and customer-related data (Eling and Lehmann 2018; EIOPA 2019; Helfand 2017; Lehrer et al. 2018). In practice, the extracted information can be applied to e-commerce to increase the probability of a purchase, but also to ease the process of a buying decision for a customer (e.g. Eling and Lehmann 2018; Gupta and Tham 2018; Owadally et al. 2019). ${ }^{4}$ Due to the high number of available data streams (e.g. conventional information of a policyholder, sensor data, social media, information of emotions) and the related methodologies to further process these, insurers have the opportunity to precisely predict or anticipate recent customer needs before and when concluding a contract (e.g. Brenner 2019; Heo and Grable 2017). ${ }^{5}$ For this reason, the literature emphasises the strengthened position with regard to sales and marketing activities (e.g. EIOPA 2019; Catlin et al. 2015; Kotalakidis et al. 2016).

To this end, the literature addresses the importance of the 'seamless' customer experience by integrating insurance products into their own respective partner websites and mobile applications or by engaging in e-commerce and online marketplaces. Insurers can also place their products on online comparison websites (e.g. Gupta and Tham 2018; Matouschek and von Hülsen 2015). In this context, the digital applications provide the basis for offering the required, convenient solutions (e.g. product bundles) via flexible channels (e.g. due to integrated customer portals and the omnichannel approach). The resulting customer experience is thus characterised by a lack of friction in relation to switching

\footnotetext{
4 The internet of things and social media help to offer tailored insurance products, e.g. by implementing machine learning, which is based on social media data, to understand users' habits and to deduct implications on related risks, which can form the basis for insurance recommendations (Spender et al. 2019).

5 With regard to applying big data (analytics), Lehrer et al. (2018) highlight clickstream and social media data, data lakes, web analytics, as well as social media analytics, predictive analytics and visualisation applications.
} 
between different channels, enabling customers to make an informed decision on a particular insurance policy, independent of time and location (e.g. Müller et al. 2015).

However, the application process can be secured, e.g. due to digital ratemaking and underwriting (Gupta and Tham 2018). In this context, the results in Table 2 point to the fact that the applications can help to enhance actuarial models with a more precise risk assessment (e.g. digital monitoring and telematics). In general, the digital applications support optimising core capabilities, such as underwriting, risk selection or claims prevention (e.g. Catlin et al. 2015, 2018). The latter, moreover, causes a shift from indemnifying losses to predicting and preventing risks, with regard to the role of an insurer (e.g. Spender et al. 2019), while the latest initiatives of insurers focus on the fields of 'mobility', 'home' and 'health' (e.g. Lang et al. 2019).

Overall, Table 2 shows that 13 out of 14 digital applications (except the digital first notification of loss) provide benefits and opportunities at the contract conclusion as customer touch point. Some digital applications with a focus on back-office functionalities (digital monitoring and telematics, digital ratemaking and underwriting, as well as fraud detection) allow insurance companies to more precisely assess risks and to improve risk selection, leading to a better pricing. The depicted applications can thus be connected to increasing customer satisfaction in the context of insurance in the context of insurance. Further digital applications such as image recognition, digital claims management or smart contracts, however, support to accelerate and automate processes. Consequently, these digital applications can enhance service quality, as well as they support to reduce costs (with the potential to lower premiums), resulting in higher customer satisfaction. Another strand of the digital applications with a focus on back-office functionalities aims to better understand customers (e.g. customer segmentation and sentiment analysis). Moreover, by using gathered information in combination with the digital applications that are assigned to the category of front-office functionalities, such as customer targeting and up- and cross-selling recommendations, insurers are able to increase service quality. Further digital applications with a focus on front-office functionalities do not only allow a more targeted customer approach, but also faster responses and better availability (chatbots or robo-advisory) on the preferred channels (omni-channel approach), also increasing service quality and thus addressing customer satisfaction.

Hence, our results show that digital applications at contract conclusion allow insurance companies to benefit in various ways from refined pricing, faster processes and customer centricity, which positively influence the components of customer satisfaction (service quality, corporate image, as well as price, and consequently the perceived value). Moreover, our results show synergies between certain digital applications (e.g. customer segmentation, customer targeting and up- and cross-selling recommendations), implying that implementing all of these respective digital applications is especially valuable for insurance companies. 


\section{Contract modifications as a customer touch point: simplifying and accelerating standard processes}

Based on the literature, the opportunities for insurers at the touch point of contract modifications range from improving the customer experience by providing fast services with sufficient capabilities, even at peak times, (e.g. Matouschek and von Hülsen 2015) to improving transparency in relation to customers' policies and the status of specific requests, e.g. by configuring standardised self-service functions (e.g. Matouschek and von Hülsen 2015; Müller et al. 2015). The applications, moreover, allow the simplification of standard processes, such as authenticating a customer employing image recognition (e.g. Shang, 2018). In addition, automation due to digital data availability reduces the manual (time intense) processing times of standard customer requests, which is especially beneficial from the perspective of optimising internal processes (e.g. Matouschek and von Hülsen 2015). Against this background, the results in Table 2 emphasise the relevance of the presented digital applications for the automation of internal processes, which primarily result in economies of time, but also prevent human error (e.g. Sharma 2019).

To summarise, Table 2 illustrates that 6 out of 14 reviewed digital applications provide considerable benefits and opportunities for insurance companies at the touch point of contract modifications. While the applications with a focus on enhancing back-office functionalities (digital ratemaking and underwriting, image recognition, digital claims management, smart contracts) positively affect insurers' key activities by simplifying and accelerating processes, digital applications with a focus on frontoffice functionalities (omni-channel approach with integrated customer portals, chatbots) particularly enable self-services for customers and improve service availability. Consequently, these selected digital applications aim to improve service quality as a component of customer satisfaction. Moreover, they have the potential to reduce costs because of increasing automation. Thus, the presented applications contribute to lower premiums that address price as a component of customer satisfaction.

\section{Event of damage as a customer touch point: creating intuitive processes for customers, with a positive impact on efficiency}

The main opportunities regarding the event of damage are reflected in the digital (and/or automated) assessment of loss and repairment costs, claims management and claims settlement, which provide the basis for creating fast and intuitive processes for the customer (e.g. Brüggemann et al. 2018; EIOPA 2019; Helfand 2017). ${ }^{6}$ For instance, handling claims can be complemented with further applications, such

\footnotetext{
${ }^{6}$ Helfand (2017) refers to transparent, app-based status reports on a claim in real time. Moreover, applying e.g. big data and artificial intelligence in this context enables the precise prediction of the attributes of claims and the clustering of claims by type and complexity, resulting in granular claims segments. This positively affects fraud detection and thus the efficiency of insurers (e.g. Brüggemann et al. 2018; EIOPA 2019).
} 
as image recognition or speech recognition for assessing or settling claims or for processing automated payments (e.g. Brüggemann et al. 2018; EIOPA 2019). ${ }^{7}$ However, due to the previously mentioned, numerous evaluable streams of customer data, a major opportunity is reflected in enhancing service management (e.g. Catlin et al. 2018): the interplay between the digital applications, e.g. digital monitoring and telematics, supports the shift from insurers' role of indemnifying losses to loss prediction and prevention (e.g. EIOPA 2019). ${ }^{8}$ In the context of customer satisfaction, the event of damage, in particular, as a major customer touch point, can be eased by the availability of (automated) additional services (e.g. Behm et al. 2019; EIOPA 2019).

Moreover, the results in Table 2 point to (digital) fraud detection, which is especially relevant, amongst further digital applications with a focus on back-office functionalities, in terms of increasing the efficiency of operations, also as a result of (partial) automation. Digital fraud detection and prevention lead to reduced operational costs, as a result of reduced fraudulent claims, but also due to released internal capacities (e.g. Deloitte 2017; EIOPA 2019; Gruhn 2018).

Overall, 9 out of the 14 digital applications provide benefits and opportunities for the event of damage as a further customer touch point (see Table 2). One strand of the applications with a focus on back-office functionalities supports insurers with reducing fraud (digital monitoring and telematics, fraud detection, image recognition, sentiment analysis) and positively affects price as a component of customer satisfaction. In this regard, the mentioned digital applications have numerous synergies; for instance, image recognition and sentiment analysis may provide valuable information for a fraud detection system. Besides, digital applications with a focus on back-office functionalities aim to automate and accelerate processes (digital claims management, smart contracts), while the applications with a focus on front-office functionalities particularly support customers in claims registration with the aim of increasing process transparency (chatbots, digital first notification of loss, omnichannel approach with integrated customer portals). For this reason, there is a clear interlinkage to increasing service quality as a component of customer satisfaction.

\section{Further contacts as a customer touch point: increasing customer interaction as a result of precise targeting}

Table 2 additionally emphasises the opportunities with regard to further contacts with customers: one major aspect refers to the identification of hidden patterns (in line with the results at the touch point of contract conclusion), which impact the measures to steer customer demand, in order to precisely attract specific target groups, e.g. customers with a high up- or cross-selling probability (e.g. Eling

\footnotetext{
7 Automated processes in this regard allow for the reduction of costs and are especially relevant for property and casualty insurance (e.g. EIOPA 2019; Brüggemann et al. 2018).

${ }^{8}$ In terms of preventing claims for health and automobile insurance, EIOPA (2019) enumerates a specific security warning (e.g. app-based), but also feedback and coaching in relation to the individual behaviour of a policyholder.
} 
and Lehmann 2018; Heo and Grable 2017). Targeting customers with personalised content allows for the compilation of personalised policy suggestions, e.g. consumption-based offerings on smartphones (Eling and Lehmann 2018; EIOPA 2019; Helfand 2017; Lehrer et al. 2018). With regard to the specific touch point, the digital applications also focus on extending the (relevant) communication with a customer over the event of damage, by generating more occasions to interact with the customer. Consequently, the utilisation of the applications helps increase the density of customer interaction (e.g. EIOPA 2019; Spender et al. 2019). Moreover, the literature points to the relevance of collaborations with external partners (e.g. Google as a tech company), which support access to non-insurance customer data to consequently attract customers (e.g. Venkatesh 2019). For instance, an ecosystem strategy is based on the shift of "acquiring customers for a specific financial product and then cross-selling other financial products over the customer lifetime" to "acquiring users with primary needs and then converting them into a customer with financial needs over the user lifetime" (Gupta and Tham 2018, p. 435). ${ }^{9}$

As Table 2 shows, 10 out of 14 digital applications provide benefits and opportunities at the touch point of further contacts. Digital applications with a focus on back-office functionalities, as well as those with a focus on front-office functionalities might, again, positively affect a customer's perception of service quality that is, for instance, due to advanced, consistent and transparent digital advice, fluent data management or the creation of explicitly addressable customer groups with automated updates for an insurance company.

\section{Discussion of limitations and requirements from the perspectives of customers and insurers}

The results of the previous section display the potential opportunities for increasing customer satisfaction at each of the major customer touch points. Our results reveal that by implementing digital applications, insurance companies can improve customer satisfaction in various ways. However, one has to take into account that the implementation of these digital applications comes with limitations and requirements from the perspective of customers as well as insurers.

Besides the benefits of more precise risk assessment and improved risk selection, as shown in the previous section, customers often have data privacy concerns in this regard (e.g. BaFin 2018; Venkatesh 2019). In certain cases, a defensive attitude of customers toward data sharing can be observed (e.g. BaFin 2018; Behm et al. 2019). Reasons for this include ethical issues and fairness concerns due to potential discrimination (e.g. BaFin 2018; EIOPA 2019; SCOR 2018). Moreover, the set of digital applications comes with increased cyber risks and risks posed by the IT. For instance, from a customer's perspective, personal data utilisation might not always be clear (EIOPA 2020) and consequently impair the potentially positive impact on

\footnotetext{
9 In this context, the literature highlights the Chinese insurer, Ping An, as an example of best practice (e.g. Catlin et al. 2018; Gupta and Tham 2018; Miehé and Lingens 2019).
} 
customer satisfaction. Even though there are very strict regulatory requirements, e.g. GDPR compliance with the regulation of using personal data (e.g. BaFin, 2018; EIOPA 2019), and potential legal requirements for data acquisition (e.g. Helfand 2017), black boxes due to the use of potentially unclear algorithms substantiate the necessity of employing trustworthy and explainable artificial intelligence (e.g. Franke 2019; Helfand 2017). Hence, in order to be able to exploit the full potential of increasing customer satisfaction due to digital applications in this regard, insurance companies have to consider the specific needs and concerns of their customers, find the right balance, and are challenged to provide a sufficient degree of transparency to customers.

Moreover, while e.g. chatbots, robo-advisory or an omni-channel approach with integrated customer portals can accelerate responses, improve availability, or enable self-services, the option for human interaction at each of the customer touch points remains important (e.g. Eckert et al. 2021; Müller et al. 2015), especially when considering customers who are less familiar with the use of digital technologies. Human interaction is, for example, relevant for the touch point of contract conclusion and the case of purchasing complex products such as life insurance policies. In this context, a robo-advisory, for instance, might not entirely replace human advice; inaccurate algorithms can cause errors that reduce the quality of the opportunities when managing customer satisfaction in practice (e.g. EIOPA 2020). To manage customer satisfaction, it is important for insurance companies to provide customers with the possibilities afforded by these digital applications but also to continue to be available in person if necessary. Insurers are required to define a balanced mix of utilising digital applications and performing physical processes, especially at interfaces with customers. Improving customer experience or accelerating operations are rather a result of combining the advantages of the digital and analog worlds instead of focusing solely on automating or digitizing them (e.g. Müller et al. 2015).

From the perspective of insurance companies, the employment of digital applications comes with specific risks (see Fig. 1). These risks require consideration, as (a) digitalization considerably intensifies their relevance (e.g. EIOPA 2020) and (b) they directly affect the relationship with customers. ${ }^{10}$ In what follows, we provide a list of the overarching concerns and issues when implementing digital applications to improve customer satisfaction from the perspective of insurers:

- Insufficient data availability, data access and data quality ${ }^{11}$

- Data security and data protection issues ${ }^{12}$

- Challenges around data processing as a result of a huge amount of (continuously) changing data ${ }^{13}$ and portability of data ${ }^{14}$

\footnotetext{
10 EIOPA $(2019$, p. 45,47$)$ provides a ranking of the opportunities and challenges facing automobile and health insurers in the limited context of big data, incorporating big data analytics.

11 See, e.g. BaFin (2018), EIOPA (2019) and Helfand (2017).

12 See, e.g. Derikx et al. (2016), EIOPA (2019) and Spender et al. (2019).

13 See, e.g. Venkatesh (2019).

14 See, e.g. EIOPA (2019).
}

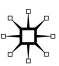


- Lack of compatible datasets to collaborate or combine insights from different data sources (e.g. relevant in the context of fraud detection) $)^{15}$

- Lack of accurate and reliable data models ${ }^{16}$ and resistance to manipulation ${ }^{17}$

- Reputational risks ${ }^{18}$ and increasing exposure to cyber risks ${ }^{19}$

Furthermore, the implementation of digital applications leads to significant change for insurance companies and entails high investment costs, especially regarding IT (e.g. Eckert and Osterrieder 2020). Apart from a lack of appropriate IT infrastructure and required facilities, the literature points to limitations due to data utilisation, the related customer attitude and regulatory requirements. For instance, as digital/automated claims management is closely related to big data and artificial intelligence, major limitations are posed by regulatory requirements, a lack of policyholders' trust with regard to the technology and data access, the necessity of precise data modelling, issues related to fairness or the ethical dilemmas surrounding black boxes, cyber risks and the related reputational risks for an insurer (e.g. BaFin 2018; EIOPA 2019, 2020). Moreover, in the context of improved customer targeting through big data, insurers need to increasingly access private customer information, which can be perceived negatively by the involved insureds (e.g. Venkatesh 2019). However, using social media data is controversially discussed; insureds are only partially poised to share social media information with insurers (e.g. Spender et al. 2019). General limitations are also a result of insufficient data quality. While data can either be entered manually or are automated, errors may occur due to human but also technical failures (Xu and Hoesch 2018). Apart from the presented limitations, further concerns for the implementation of each digital application also incorporate skilled worker shortage, general project risks, as well as issues of compatibility with the corporate culture (e.g. BaFin 2018; EIOPA 2019).

To utilise the previously explained opportunities at each customer touch point, insurers must consider numerous requirements, based on the literature. For this reason, Table A1 in the Appendix provides a set of major requirements, clustered for each digital application.

\section{Conclusion}

In this article, we comprehensively analyse a set of digital applications, including their benefits for insurers, when managing customer satisfaction. Based on an extensive analysis of the literature, we first present the digital applications with their characteristics and state their relevance by clustering their beneficial effects in relation to customer satisfaction at each of the four customer touch points, namely, contract conclusion,

\footnotetext{
15 See, e.g. Garde (2017).

16 See, e.g. EIOPA (2019).

17 See, e.g. Shang (2018) and Spender et al. (2019).

18 See, e.g. EIOPA (2019) and Shang (2018).

19 See, e.g. BaFin (2018), Gatteschi et al. (2018), SCOR (2018) and Shang (2018).
} 
contract modifications, the event of damage as the moment-of-truth and further contacts. In addition, we focus on the limitations and address specific concerns that accompany the utilisation of digital technologies (e.g. artificial intelligence, cloud computing). Based on this, we address the specific requirements for each digital application.

The main findings substantiate how the set of digital applications strengthens the position of sales and marketing, simplifying and accelerating (standard) processes, along with creating intuitive processes for customers, increasing efficiency and enhancing the density of customer interaction. In the context of customer satisfaction in the insurance industry, the results indicate the positive effects on a customer's perception of service quality along with the perceived value, which have been previously defined as the components of customer satisfaction within the theoretical framework of the paper. Moreover, we emphasise the opportunity to offer more attractive pricing for the customer, which might affect the perception of price as a further driver of customer satisfaction.

However, the implementation of digital applications results in high investment costs for insurance companies. As managing customer satisfaction poses a major strategic challenge, we emphasise the strategic relevance of defining a selected portfolio of digital applications over the course of an insurer's holistic digital strategy. The strategic implications from the depicted 'opportunity landscape' thus depend on each specific insurer, as, for instance, the service leader might prioritise digital applications to foster service quality or the perceived value, while cost leaders might prefer to design their business processes (in general, but also at the customer touch points) more efficiently, with an impact on price.

Currently, the academic research on customer satisfaction management in insurance companies is rather limited, especially with a focus on the opportunities resulting from digital transformation. While our paper provides an overview of opportunities for customer satisfaction management based on digital applications, further research should empirically investigate whether (and to which degree) customer satisfaction of insurance companies that increasingly implement the presented digital applications improves. Moreover, since transparency is an important factor for insurance customers, future research should particularly focus on explainable artificial intelligence to increase the transparency of digital applications and therefore win the trust of customers and fully exploit the potential of digital applications.

\section{Appendix}

See Table A1. 


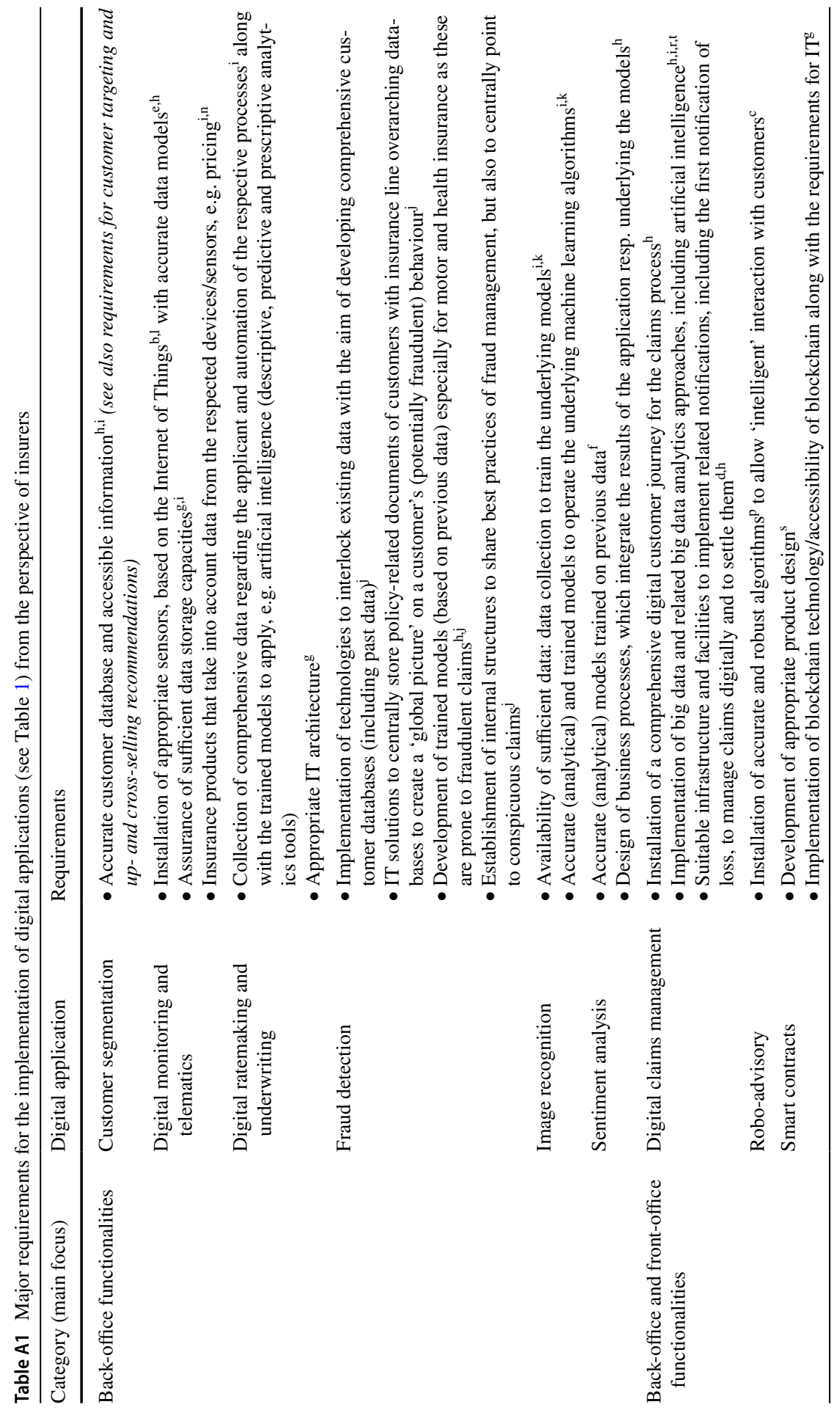




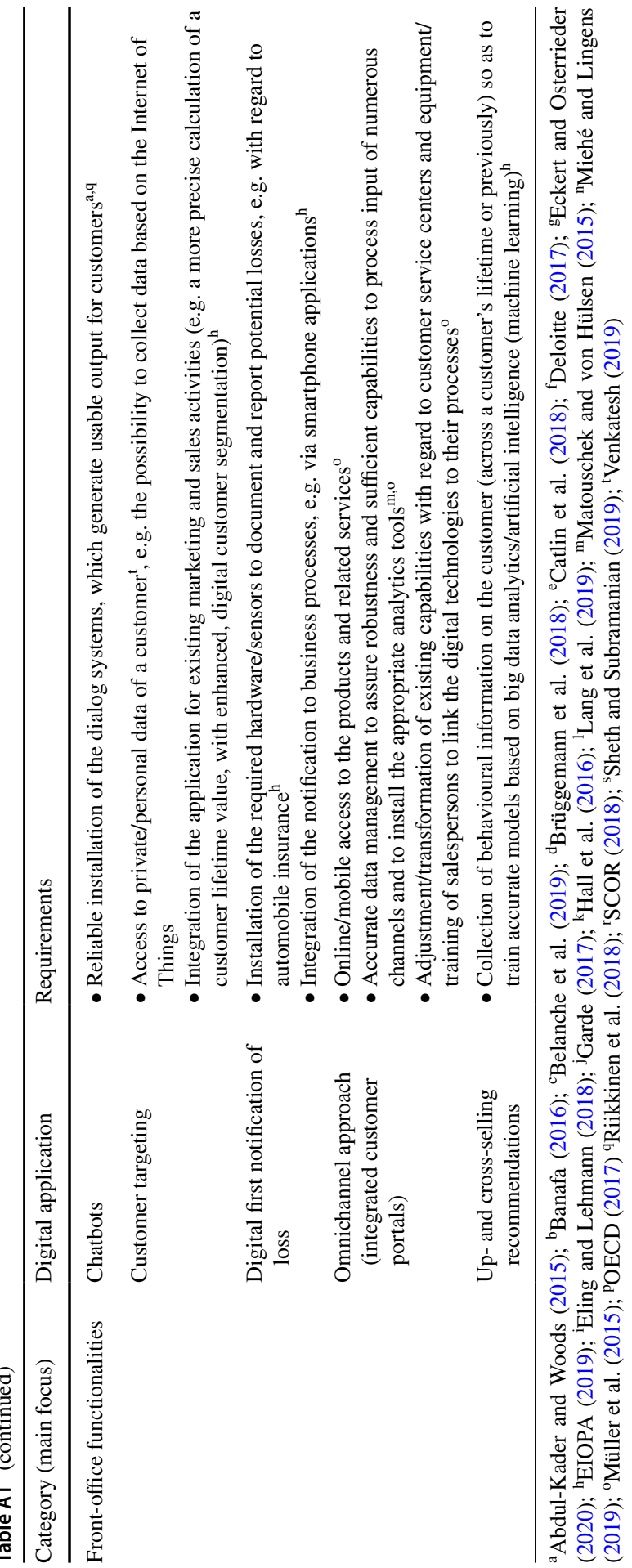

称 
Funding Open Access funding enabled and organized by Projekt DEAL.

\section{Declarations}

Conflict of interest On behalf of all authors, the corresponding author states that there is no conflict of interest.

Open Access This article is licensed under a Creative Commons Attribution 4.0 International License, which permits use, sharing, adaptation, distribution and reproduction in any medium or format, as long as you give appropriate credit to the original author(s) and the source, provide a link to the Creative Commons licence, and indicate if changes were made. The images or other third party material in this article are included in the article's Creative Commons licence, unless indicated otherwise in a credit line to the material. If material is not included in the article's Creative Commons licence and your intended use is not permitted by statutory regulation or exceeds the permitted use, you will need to obtain permission directly from the copyright holder. To view a copy of this licence, visit http://creativecommons.org/licen ses/by/4.0/.

\section{References}

Abdul-Kader, S.A., and J. Woods. 2015. Survey on chatbot design techniques in speech conversation systems. International Journal of Advanced Computer Science and Applications 6 (7): 72-80.

Abu-Salim, T., P.O. Okey, T. Harrison, and V. Lindsay. 2017. Effects of perceived cost, service quality, and customer satisfaction on health insurance service continuance. Journal of Financial Services Marketing 22 (4): 173-186.

Aksoy, L., B. Cooil, C. Groening, T.L. Keiningham, and A. Yalçın. 2008. The long-term stock market valuation of customer satisfaction. Journal of Marketing 72 (4): 105-122.

Anderson, E.W., C. Fornell, and S.K. Mazvancheryl. 2004. Customer satisfaction and shareholder value. Journal of Marketing 68 (4): 172-185.

Anjum, U., J. Aftab, Q. Sultan, and M. Ahmed. 2016. Factors affecting the service quality and customer satisfaction in telecom industry of Pakistan. International Journal of Management, Accounting and Economics 3 (9): 509-520.

Arora, P., and S. Narula. 2018. Linkages between service quality, customer satisfaction and customer loyalty: A literature review. IUP Journal of Marketing Management 17 (4): 30-54.

Baecke, B., and L. Bocca. 2017. The value of vehicle telematics data in insurance risk selection processes. Decision Support Systems 98: 69-79.

Baron, R., and M. Chaudey. 2019. Blockchain and smart-contract: A pioneering approach of interfirms relationships? The Case of Franchise Networks. Working Paper, University of Lyon. Retrieved August 25, 2021 from https://ssrn.com/abstract=3378477.

Belanche, D., L.V. Casaló, and C. Flavián. 2019. Artificial intelligence in finTech: Understanding robo-advisors adoption among customers. Industrial Management \& Data Systems 119 (7): $1411-1430$.

Brennen, J.S., and D. Kreiss. 2016. Digitalization. In The International Encyclopedia of Communication Theory and Philosophy, 1st ed., ed. K.B. Jensen and R.T. Craig, 556-566. Hoboken: Wiley.

Brutyan, A., D. Guxha, and H. Schmeiser. 2019. Versicherungen aus Kundensicht: Erkenntnisse aus der Wissenschaft. Zeitschrift für die gesamte Versicherungswissenschaft 108: 365-381.

Cebulsky, M., J. Günther, P. Heidkamp, and F. Brinkmann. 2018. The digital insurance - facing customer expectation in a rapidly changing world. In Digital marketplaces unleashed, ed. C. Linnhoff-Popien, R. Schneider, and M. Zaddach, 359-370. Berlin: Springer.

Chen, C.C.V., and C.J. Chen. 2017. The role of customer participation for enhancing repurchase intention. Management Decision 55 (3): 547-562.

Derikx, S., M. De Reuver, and M. Kroesen. 2016. Can privacy concerns for insurance of connected cars be compensated? Electronic Markets 26 (1): 73-81.

Dodds, W.B., K.B. Monroe, and D. Grewal. 1991. Effects of price, brand, and store information on buyers' product evaluations. Journal of Marketing Research 28 (3): 307-319. 
Dominique-Ferreira, S. 2018. The key role played by intermediaries in the retail insurance distribution. International Journal of Retail and Distribution Management 46 (11-12): 1170-1192.

Eckert, C., J. Eckert, and A. Zitzmann. 2021. The Status Quo of Digital Transformation in Insurance Sales: An Empirical Analysis of the German Insurance Industry. Working Paper, Friedrich-Alexander University Erlangen-Nürnberg (FAU).

Eckert, C., and K. Osterrieder. 2020. How digitalization affects insurance companies: Overview and use cases of digital technologies. Zeitschrift für die gesamte Versicherungswissenschaft 109 (5): 333-360.

Eling, M., and M. Lehmann. 2018. The impact of digitalization on the insurance value chain and the insurability of risks. The Geneva Papers on Risk and Insurance: Issues and Practice 43 (3): 359-396.

Eskildsen, J., and K. Kristensen. 2008. CusCustomer satisfaction and customer loyalty as predictors of future business potential. Total Quality Management 19 (7-8): 843-853.

Fornell, C. 1992. A national satisfaction barometer: The Swedish experience. Journal of Marketing 56 (1): 6-21.

Fornell, C., M.D. Johnson, E.W. Anderson, J. Cha, and B.E. Bryant. 1996. The american customer satisfaction index: Nature, purpose, and findings. Journal of Marketing 60 (4): 7-18.

Fornell, C., S. Mithas, F.V. Morgeson III., and M.S. Krishnan. 2006. Customer satisfaction and stock prices: High returns, low risk. Journal of Marketing 70 (1): 3-14.

Fornell, C., F.V. Morgeson III., and G.T.M. Hult. 2016. Stock returns on customer satisfaction do beat the market: Gauging the effect of a marketing intangible. Journal of Marketing 80 (5): 92-107.

Franke, U. 2019. Towards increased transparency in digital insurance. ERCIM NEWS 116: 23-24.

Garde, M.D. 2017. Fraud management in insurance claims. The Journal of Insurance Institute India 2017: 11-13.

Gatteschi, V., F. Lamberti, C. Demartini, C. Pranteda, and V. Santamaría. 2018. Blockchain and smart contracts for insurance: Is the technology mature enough? Future Internet 10 (2): 1-16.

Gatzert, N., and K. Osterrieder. 2020. The future of mobility and its impact on the automobile insurance industry. Risk Management and Insurance Review 23 (1): 31-51.

Giese, J.L., and J.A. Cote. 2000. (2000): Defining customer satisfaction. Academy of Marketing Science Review 1: 1-22.

Grima, S., J. Spiteri, and I. Romānova. 2020. A STEEP framework analysis of the key factors impacting the use of blockchain technology in the insurance industry. The Geneva Papers on Risk and Insurance: Issues and Practice 45 (3): 398-425.

Gruca, T.S., and L.L. Rego. 2005. Customer satisfaction, cash flow, and shareholder value. Journal of Marketing 69 (3): 115-130.

Grösch, M., and M. Steul-Fischer. 2017. Defaults and advice in self-customization procedures of insurance. Zeitschrift für die gesamte Versicherungswissenschaft 106 (3-4): 325-341.

Gruhn, V. 2018. Versicherungen: Von natur aus für Künstliche intelligenz geeignet. Wirtschaftsinformatik \& Management 10 (4): 104-111.

Gupta, P., and T.M. Tham. 2018. Fintech (the new DNA of financial services). Boston: Walter de Gruyter.

Günzel, F., and A.B. Holm. 2013. One size does not fit all - understanding the front-end and back-end of business model innovation. International Journal of Innovation Management 17 (1): 1340002.

Hall, S.N. 2017. How artificial intelligence is changing the insurance industry. CIPR Newsletter 22 (2017): 1-8.

Helfand, R.D. 2017. Big data and insurance: What lawyers need to know and understand. Journal of Internet Law 21 (3): 2-35.

Helgesen, Ø. 2006. Are loyal customers profitable? customer satisfaction, customer (action) loyalty and customer profitability at the individual level. Journal of Marketing Management 22 (3-4): 245-266.

Heo, W., and J.E. Grable. 2017. Demand for life insurance: A consumer perspective. Economics \& Investment Management 71 (3): 19-22.

Heskett, J.L., T.O. Jones, G.W. Loveman, W.E. Sasser Jr., and L.A. Schlesinger. 1994. Putting the service profit chain to work. Harvard Business Review 10: 105-111.

Hill, J., W.R. Ford, and I.G. Farreras. 2015. Real conversations with artificial intelligence: A comparison between human-human online conversations and human-chatbot conversations. Computers in Human Behavior 49: 245-250.

Jahnert, J.R., and H. Schmeiser. 2021. The relationship between net promoter score and insurers' profitability: An empirical analysis at the customer level. The Geneva Papers on Risk and Insurance: Issues and Practice. https://doi.org/10.1057/s41288-021-00237-3. 
Ittner, C.D., and D.F. Larcker. 1998. Are nonfinancial measures leading indicators of financial performance? An analysis of customer satisfaction. Journal of Accounting Research 36: 1-35.

Johnston, R. 1995. The determinants of service quality: Satisfiers and dissatisfiers. International Journal of Service Industry Management 6 (5): 53-71.

Kelley, K.H., L.M. Fontanetta, M. Heintzman, and N. Pereira. 2018. Artificial intelligence: Implications for social inflation and insurance. Risk Management and Insurance Review 21 (3): 373-387.

Kreuzer, T., M. Röglinger, and L. Rupprecht. 2020. Customer-centric prioritization of process improvement projects. Decision Support Systems 133: 113286.

Lee, C.Y. 2019. Does corporate social responsibility influence customer loyalty in the Taiwan insurance sector? The role of corporate image and customer satisfaction. Journal of Promotion Management 25 (1): 43-64.

Lehrer, C., A. Wieneke, J. Vom Brocke, R. Jung, and S. Seidel. 2018. How big data analytics enables service innovation: Materiality, affordance, and the individualization of service. Journal of Management Information Systems 35 (2): 424-460.

Leischnig, A., K. Kasper-Brauer, and S.C. Thornton. 2018. Spotlight on customization: An analysis of necessity and sufficiency in services. Journal of Business Research 89: 385-390.

Lyskawa, K., A. Kedra, L. Klapkiv, and J. Klapkiv. 2019. Digitalization in insurance companies. Contemporary Issues in Business, Management and Economics Engineering, Conference Paper 2019.

Maedche, A., S. Morana, S. Schacht, D. Werth, and J. Krumeich. 2016. Advanced user assistance systems. Business \& Information Systems Engineering 58 (5): 367-370.

Márquez, A.C. 2010. Dynamic modelling for supply chain management: Dealing with front-end, backend and integration Issues. London: Springer.

Matouschek, G., and B. von Hülsen. 2015. Auf dem Weg zum Omni-Kanal. In Change management in Versicherungsunternehmen, ed. G. Zimmermann, 335-352. Wiesbaden: Springer Gabler.

Matzler, K., and H.H. Hinterhuber. 1998. How to make product development projects more successful by integrating Kano's model of customer satisfaction into quality function deployment. Technovation 18 (1): $25-38$.

Mau, S., I.P. Cvijikj, and J. Wagner. 2015. From research to purchase: An empirical analysis of researchshopping behaviour in the insurance sector. Zeitschrift für die gesamte Versicherungswissenschaft 104 (5): 573-593.

Miehé, L., and B. Lingens. 2019. Ecosystems als Wunderwaffe? Schweizer Versicherung 31 (8-9): 45-49.

Mittal, V., and W.A. Kamakura. 2001. Satisfaction, repurchase intent, and repurchase behavior: Investigating the moderating effect of customer characteristics. Journal of Marketing Research 38 (1): $131-142$.

Nguyen, H.T., H. Nguyen, N.D. Nguyen, and A.C. Phan. 2018. (2018): Determinants of customer satisfaction and loyalty in Vietnamese life-insurance setting. Sustainability 10: 1151.

Oliver, R.L. 1977. Effect of expectation and disconfirmation on postexposure product evaluations - an alternative interpretation. Journal of Applied Psychology 62 (4): 480-486.

Oliver, R.L. 1980. A cognitive model of the antecedents and consequences of satisfaction decisions. Journal of Marketing Research 17 (4): 460-469.

Osterwalder, A., and Y. Pigneur. 2010. Business model generation: A handbook for visionaries, game changers, and challengers. Hoboken: Wiley.

Owadally, I., F. Zhou, R. Otunba, J. Lin, and D. Wright. 2019. Time series data mining with an application to measure of underwriting cycles. North American Actuarial Journal 23 (3): 469-484.

Parasuraman, A. 1997. Reflections on gaining competitive advantage through customer value. Journal of the Academy of Marketing Science 25 (2): 154-161.

Parasuraman, A., V.A. Zeithaml, and L.L. Berry. 1988. SERVQUAL: A multiple-item scale for measuring consumer perceptions of service quality. Journal of Retailing 64 (1): 12-40.

Phoon, K., and F. Koh. 2017. Robo-advisors and wealth management. The Journal of Alternative Investments 20 (3): 79-94.

Pooser, D.M., and M.J. Browne. 2018. The effects of customer satisfaction on company profitability: Evidence from the property and casualty insurance industry. Risk Management and Insurance Review 21 (29): 289-308.

Ramamoorthy, R., A. Gunasekaran, M. Roy, B.K. Rai, and S.A. Senthilkumar. 2018. Service quality and its impact on customers' behavioural intentions and satisfaction: An empirical study of the Indian life insurance sector. Total Quality Management and Business Excellence 29 (7-8): 834-847.

Reichheld, F.F., and W.E. Sasser. 1990. Zero defections: Quality comes to services. Harvard Business Review 68 (5): 105-111. 
Ruefenacht, M. 2018. The role of satisfaction and loyalty for insurers. International Journal of Bank Marketing 36 (6): 1034-1054.

Riikkinen, M., H. Saarijärvi, P. Sarlin, and I. Lähteenmäki. 2018. Using artificial intelligence to create value in insurance. International Journal of Bank Marketing 36 (6): 1145-1168.

Savić, D. 2019. From digitization, through digitalization, to digital transformation. Online Searcher 43 (1): 36-39.

Sharma, S. 2019. Artificial intelligence in insurance sector. The Journal of Insurance Institute India 2019: 59-61.

Sheth, A., and H. Subramanian. 2019. Blockchain and contract theory: Modeling smart contracts using insurance markets. Managerial Finance 46 (6): 803-814.

Singer, A.W. 2019. Can blockchain improve insurance? Risk Management 66 (1): 20-25.

Sironi, P. 2016. FinTech innovation: From robo-advisors to goal based investing and gamification. Hoboken: Wiley.

Spender, A., C. Bullen, L. Altmann-Richer, J. Cripps, R. Duffy, C. Falkous, M. Farrell, T. Horn, J. Wigzell, and W. Yeap. 2019. Wearables and the internet of things: Considerations for the life and health insurance industry. British Actuarial Journal 24 (22): 1-31.

Steiner, P.H., and P. Maas. 2018. When customers are willing to disclose information in the insurance industry: A multi-group analysis comparing ten countries. International Journal of Bank Marketing 36 (6): 1015-1033.

Trautinger, M.J. 2015. Der Moment der Wahrheit - Eine empirische Untersuchung der Zufriedenheitsfaktoren im Versicherungsschadenfall. Zeitschrift für die gesamte Versicherungswissenschaft 104: 289-309.

Venkatesh, S. 2019. Big data - can it make a big impact in the insurance sector? The Journal Insurance Institute of India 6 (6): 92-97.

Verbelen, R., K. Antonio, and G. Claeskens. 2018. Unravelling the predictive power of telematics data in car insurance pricing. Journal of the Royal Statistical Society: Series C (Applied Statistics) 67 (5): 1275-1304.

Woo-Yeon, P., S.J. Lee, C. Park, S. Jung, and H.K. Kim. 2021. The effect of service quality of internet insurance on intention to purchase online. International Journal of Smart Business and Technology 9 (1): $63-70$.

Xu, J., and A. Hoesch. 2018. Predicting longevity: An analysis of potential alternatives to life expectancy reports. The Journal of Retirement 2018: 9-24.

Zeithaml, V.A., A. Parasuraman, and L.L. Berry. 1990. Delivering service quality (balancing customer perceptions and expectations). New York: Free Press.

\section{Web-References}

AssCompact. 2020. So steht es um die Kundenzufriedenheit in der Versicherungswelt. Retrived 18 January 2021 from https://www.asscompact.de/nachrichten/so-steht-es-um-die-kundenzufrieden-heitder-versicherungswelt.

BaFin. 2018. Big Data Trifft auf Künstliche Intelligenz. Retrieved 15 August 2021 from https://www. bafin.de/SharedDocs/Downloads/DE/dl_bdai_studie.pdf?_blob=publicationFile \&v=3.

Banafa, A. 2016. IoT Standardization and Implementation Challenges. IEEE Internet of Things Newsletter. Retrieved 27 September 2021 from https://iot.ieee.org/newsletter/july-2016/iot-standardizationand-implementation-challenges.html.

Behm, S., U. Deetjen, S. Kaniyar, N. Methner, \& B. Münstermann. 2019. Digital Ecosystems for Insurers: Opportunities through the Internet of Things. Retrieved 26 January 2021 from https://www. mckinsey.com/ /media/McKinsey/Industries/Financial\%20Services/Our\%20Insights/Digital\%20eco systems\%20for\%20insurers\%20Opportunities\%20through\%20the\%20Internet\%20of\%20Things/ Digital-ecosystems-for-insurers-Opportunities-through-the-Internet-of-Things.ashx.

Bitkom. 2018. Digitalisierung gestalten mit dem Periodensystem der Künstlichen Intelligenz. Ein Navigationssystem für Entscheider. Retrieved 15 September 2021, from https://www.bitkom.org/sites/ defaults/files/2018-12/181204_LF_Periodensystem_online_0.pdf. 
Brenner, M. 2019. How to Improve Customer Segmentation with AI. Retrieved 30 January 2021, from https://marketinginsidergroup.com/artificial-intelligence/how-to-improve-customer-segmentati on-with-ai/.

Brüggemann, P., T. Catlin, J. Chinczewski, J.-T. Lorenz, and S. Prymaka. 2018. Claims in the Digital Age: How Insurers Can Get Started. Retrieved 31 March 2021 from https://www.mckinsey.com/ industries/financial-services/our-insights/digital-insurance-in-2018-driving-real-impact-with-digit al-and-analytics.

Catlin, T., R. Hartmann, I. Segev, and R. Tentis. 2015. The Making of a Digital Insurer: The Path to Enhanced Profitability, Lower Costs and Stronger Customer Loyalty. Retrieved 17 May, 2021 from http://www.mckinsey.com/industries/financial-services/our-insights/the-making-of-a-digital-insurer.

Catlin, T., J.H. Lorenz, J. Nandan, S. Sharma, and A. Waschto, A. 2018. Insurance Beyond Digital: The Rise of Ecosystems and Platforms. Retrieved 17 May 2021 from https://www.mckinsey.com/indus tries/financial-services/our-insights/insurance-beyond-digital-the-rise-of-ecosystems-and-platforms.

Deloitte. 2017. From Mystery to Mastery: Unlocking the Business Value of Artificial Intelligence in the Insurance Industry. Retrieved 25 August 2021 from https://www2.deloitte.com/content/dam/Deloi tte/ie/Documents/Technology/IE_Insurance\%20Whitepaper_0318.pdf.

EIOPA. 2019. Big Data Analytics in Motor and Health Insurance: A Thematic Review. Retrieved 31 May 2021 from https://www.eiopa.europa.eu/content/big-data-analytics-motor-and-health-insurance_en.

EIOPA. 2020. Discussion Paper on the (Re)Insurance Value Chain and New Business Models Arising from Digitalisation. Retrieved 16 August September 2021 from https://www.eiopa.europa.eu/conte nt/discussion-paper-reinsurance-value-chain-and-new-business-models-arising-digitalisation.

Hall, P., W. Phan, and K. Whitson. 2016. The Evolution of Analytics: Opportunities and Challenges for Machine Learning in Business. Retrieved 15 January, 2021 from https://www.sas.com/content/dam/ SAS/en_us/doc/whitepaper2/evolution-of-analytics-108240.pdf.

IAIS. 2018. Issues Paper on the Increasing Use of Digital Technology in Insurance and Its Potential Impact on Consumer Outcomes. Retrieved 15 January 2021 from https://www.iaisweb.org/page/ supervisory-material/issuespapers/file/77816/issues-paper-on-increasing-digitalisation-in-insur ance-and-its-potential-imapct-on-consumer-outcomes.

Kotalakidis, N., H. Naujoks, and F. Müller. 2016. Digitalisierung der Versicherungswirtschaft: Die 18-Milliarden-Chance. Retrieved 15 August 2021 from https:/www.bain.com/contentassets/47d31 2fae3a94e9d9629c66d078243ab/bain-googlestudie_digitalisierung_der_versicherungswirtschaft_ ds_final.pdf.

Lang, N., K. von Szczepanski, and C. Wurzer. 2019. The Emerging Art of Ecosystem Management. Boston Consulting Group and BCG Henderson Institute. Retrieved 21 February 2021 from https:// image-src.bcg.com/Images/BCG-The-Emerging-Art-of-Ecosystem-Management-Jan-2019-rev_ tcm27-212792.pdf.

Maas, P., L. Fischer, C. Schumacher, and M. Bieler. 2019. Beyond Insurance 2030: Neue Rollen für Versicherer im branchenübergreifenden Wettbewerb. Retrieved 21 February 2021 from https://www. alexandria.unisg.ch/256710/1/Beyond\%20insurance\%202030.pdf.

Müller, F., H. Naujoks, H. Singh, G. Schwarz, A. Schwedel, and K. Thomson. 2015. Global Digital Insurance Benchmarking Report 2015. Retrieved 21 February 2021 from http://www.bain.com/images/ GLOBAL-DIGITAIINSURANCE-2015.pdf.

OECD. 2017. Technology and Innovation in the Insurance Sector. Retrieved 21 February 2021 from https://www.oecd.org/pensions/Technology-and-innovation-in-the-insurance-sector.pdf.

Schmidt, C. 2018. Insurance in the Digital Age: A View on Key Implications for the Economy and Society. The Geneva Association. Retrieved 8 August 2021 from https://www.genevaassociation.org/ research-topics/digitalization/insurance-digital-age.

SCOR. 2018. The Impact of Artificial Intelligence on the (Re)Insurance Sector. Retrieved 29 January 2021 from https://www.scor.com/sites/default/files/focus_scor-artificial_intelligence.pdf.

Shang, K. 2018. Applying Image Recognition to Insurance. Retrieved 26 July 2021 from https://www. soa.org/globalassets/assets/Files/resources/research-report/2018/applying-image-recognition.pdf.

Tabrizi, B., E. Lam, K. Girard, and V. Irvin. 2019. Digital Transformation is not About Technology. Retrieved 31 May 2021 from https://hbr.org/2019/03/digital-transformation-is-not-about-technology.

Publisher's Note Springer Nature remains neutral with regard to jurisdictional claims in published maps and institutional affiliations. 


\section{About the authors}

Christian Eckert studied Mathematics at the Friedrich-Alexander University Erlangen-Nürnberg (FAU). After his doctorate, he gathered industry experience at NÜRNBERGER Versicherung, where he worked as an actuary and venture capital manager. He is a professional actuary of the German Association of Actuaries (DAV). Currently, Christian Eckert is Professor of Insurance and IT Management at Coburg University of Applied Sciences and Arts. His main research interests include digital transformation in insurance, actuarial data science and risk management.

Christof Neunsinger holds a Master of Science in Finance, Auditing, Controlling and Taxation from the Friedrich-Alexander University Erlangen-Nürnberg, and is a Ph.D. student at the Department of Accounting and Management Control at the Friedrich-Alexander University Erlangen-Nürnberg (FAU) in Nürnberg, Germany. His research interests include automation of finance, corporate governance and risk management.

Katrin Osterrieder holds a Master of Science in Finance, Auditing, Controlling and Taxation from the Friedrich-Alexander University Erlangen-Nürnberg, and is a Ph.D. student at the Department of Insurance Economics and Risk Management at the Friedrich-Alexander University Erlangen-Nürnberg (FAU) in Nürnberg, Germany. Her research interests include the impact of future of mobility on insurance and (digital) business models in the insurance industry. 